\title{
Is Public Capital Really Productive? A Methodological Reappraisal
}

\author{
Christophe Hurlin* and Alexandru Minea ${ }^{\dagger}$
}

Revised December 2012

\begin{abstract}
We present an evaluation of the main empirical approaches used in the literature to estimate the contribution of public capital stock to growth and private factors' productivity. Based on a simple stochastic general equilibrium model, built as to reproduce the main long-run relations observed in US post-war historical data, we show that the production function approach may not be reliable to estimate this contribution. Our analysis reveals that this approach largely overestimates the public capital elasticity, given the presence of a common stochastic trend shared by all non-stationary inputs.
\end{abstract}

- Keywords : (I) Robustness and sensitivity analysis, (I) Stochastic processes, (I) Time series, Infrastructure, Public capital elasticity, Cointegrated regressors.

- J.E.L Classification: H54, C15, C32.

${ }^{*}$ LEO, University of Orléans. Rue de Blois. BP 6739. 45067 Orléans Cedex 2. France. email: christophe.hurlin@univ-orleans.fr.

${ }^{\dagger}$ Corresponding author: CERDI, University of Auvergne. 65, Bd. Fr. Mitterrand. BP 320. 63009 Clermont-Ferrand Cedex 1. France. email: alexandru.minea@u-clermont1.fr.

We are indebted to two anonymous Referees and to the Editor (I. Bomze) for very valuable remarks on a previous version of this paper. Usual disclaimers apply. 


\section{Introduction}

Economists and political leaders generally consider public infrastructure investments as a way of sparking economic development over the forthcoming decades. The basic idea is that these investments may enhance the productivity of private factors, and thereby stimulate private investment expenditure and production. However, if this view seems to be broadly accepted, the conclusions are not so clear-cut when it comes to measuring these effects. Two methodological approaches were widely used for estimating the productive contribution of infrastructures (see Romp and De Haan 2007 for a survey). The first and most popular consists in estimating an expanded production function, including the public capital stock as input, specified in levels. Applied to aggregate series (Aschauer 1989, Munnell 1990), this method leads to strikingly high estimates of public capital elasticity, and consequently to implicit rates of return much higher than those observed on the private capital.

The second approach consists in estimating the same type of production function, but with a specification in first differences. Indeed, several empirical studies on American data (Aaron 1990, Tatom 1991, Sturm and De Haan 1995, Crowder and Himarios 1997), highlighted the absence of a cointegrating relationship between output and (public and private) inputs. Such an outcome implies that the total productivity of private factors is non stationary (as most macroeconomic series), and thus the technological function can not be considered as a long term relationship. However, when this issue is tackled by estimating the production function in first differences, the estimated elasticity of public capital is often not significantly different from zero. This not only challenges the validity of Aschauer's (1989) findings, but also casts doubt on the existence of a macroeconomic productive effect of public infrastructures (Tatom 1991).

This large range observed in the empirical results leads us to suggest a sensitivity analysis of these approaches. More precisely, the aim of this paper is to identify the bias sources which could affect the estimates of public capital elasticity and to assess the magnitude of these biases. ${ }^{1}$ To this end, we consider a theoretical Data Gener-

\footnotetext{
${ }^{1}$ Our general approach that consists in evaluating both theoretically and empirically the main empirical approaches generally used to estimate the efficiency of public capital is in line with recent works that aim at evaluating the efficiency of public good provision in general. For example, in another context, De Witte and Geys (2013) show that citizens' coproduction of public services requires a careful reassessment of how we approach the measurement of productive efficiency in public service delivery, as using observable outcomes (e.g., library circulation, school results, etc.) as output indicators is inappropriate and leads to biased estimates.
} 
ating Process (DGP) in line with the standard theoretical representations of growth and public capital productivity. The DGP consists of a very usual dynamic stochastic general equilibrium (DSGE) model directly derived from the growth model coined by Barro (1990). This model was built such as to reproduce, under an appropriate calibration, the dynamics of the US economy, as this was the case in the early DSGE literature. However, contrary to the moment-based strategy adopted in the DSGE literature, we give special attention to a particularly crucial neglected dimension, namely the stationarity (non stationarity / cointegration) properties of the series. ${ }^{2}$

We proceed as follows. First, we show that our DGP (i.e. our DSGE model) has a reduced form that simply corresponds to a constrained $V A R I M A$. Next, given this $V A R I M A$ form, we derive the exact asymptotic distribution of the estimators of the public capital elasticity for various regression models usually used in the empirical literature. This analysis allows deriving the asymptotic bias of the estimators, and more interestingly, explaining the source of this bias. To the best of our knowledge, it constitutes the first attempt to provide a theoretical explanation of the empirical puzzle of the public capital productivity estimates. Finally, we investigate the finite sample bias, using Monte Carlo simulations, by comparing the estimators on simulated data and the calibrated value of public capital elasticity. ${ }^{3}$

Our results are the following. It first appears that the standard approach, relying on the direct estimate of the production function specified in levels, leads to an overestimation of the productive contribution of public infrastructures. Given the longrun properties of the theoretical model, we prove that this asymptotic bias is due to the presence of a stochastic common trend between private and public capital stocks, which imposes a fallacious asymptotic constraint forcing the public capital elasticity to be equal to the labor elasticity. ${ }^{4}$ Second, the finite sample analysis based on Monte Carlo simulations confirms our theoretical findings. Even for relatively small sample sizes, the estimation on levels leads to a positive bias of the public capital elasticity

\footnotetext{
${ }^{2}$ According to Crowder and Himarios (1997), these properties are: (i) all series, except employment, are integrated I(1), but (ii) the ratios of these integrated series are stationary. In other words, production, public and private investment, public and private capital stocks are non stationary, but all these couples of series are cointegrated with a cointegrating vector defined by $(1,-1)$. Since our DGP reproduces these properties, it can be considered as an accurate representation of the US economy (due to our calibration) and can be extended to other economies (using appropriate calibration).

${ }^{3}$ We would like to thank the Referees for this suggestion.

${ }^{4}$ In addition, we emphasize a second bias source, namely the traditional endogeneity bias due to the simultaneous determination of public capital and private factor productivity.
} 
and the estimation on first differences leads to a downward bias and to a reduction in the power of standard tests. Consequently, our analysis shows that first differencing the data leads to spurious inferences about the public capital elasticity.

These findings imply that the correct strategy to estimate the public capital elasticity consists in withdrawing the common stochastic trends from the non-stationary regressors (and only for these regressors). On the contrary, the approach based on first differences, proposed by Tatom (1991), leads to differentiate the dependent variable and all the regressors. Our paper suggests that this transformation has not to be done for the dependent variable and for all the regressors, but only for the regressors that share the common stochastic trend.

The paper is organized as follows. Section 2 surveys the empirical puzzle on the infrastructure returns. Section 3 presents the DSGE model, which is then written in an econometric form in section 4 . Section 5 is devoted to characterizing the analytical properties of estimators, while section 6 provides finite sample results based on Monte Carlo simulations, and 7 concludes.

\section{The empirical puzzle}

During the late 1980's and the 1990's, a huge empirical literature has been devoted to the estimation of the rate of return on public capital (see Gramlich, 1994, for a survey). If we stick to the most influential studies, namely those based on time series, two methodological approaches were employed. First, the direct estimate of a production function expanded to the stock of public capital. Applied to aggregate data, with a specification in level of the production function, this method generally tends to prove the existence of an important productive contribution of public infrastructures. Indeed, since the seminal article of Aschauer (1989), many empirical studies embraced this methodology and outlined statistically significant estimated elasticities, on American data as well as on OECD data sets (see Table 1).

However, it should be noticed that in these estimations the productive contributions of private factors are generally lower than the share of their respective remuneration in added value. Besides, in Aschauer (1989), Eisner (1994), Vijverberg et al. (1997) or Sturm and De Haan (1995), the elasticity of private capital is lower than that of public capital or equal to it, while the elasticity of labor is even negative under some specifica- 
tions considered by Munnell (1990) or Sturm and De Haan (1995). Furthermore, if we accept such estimates as relevant, the implied annual marginal yield of public capital is strikingly high. For example, Tatom (1991) or Gramlich (1994) computed, on the basis of elasticities estimated by Aschauer (1989), that the annual marginal productivity of public infrastructures would lie between $75 \%$ in 1970 and more than $100 \%$ in 1991, meaning that "one unit of government capital pays for itself in terms of higher output in a year or less, which does strike one as implausible" (Gramlich 1994, page 1186).

Table 1: Main Empirical Results: Specifications in Level

\begin{tabular}{lcccccc}
\hline \hline \multicolumn{1}{c}{ Study } & Data & Method & Model & $e_{g}$ & $e_{k}$ & $e_{n}$ \\
Ratner (1983) & & & & & & \\
Aschauer (1989) & USA (49-73) & AR(1) & OCRS & $\mathbf{0 . 0 6}$ & 0.22 & 0.72 \\
Ram and Ramsey (1989) & USA (49-85) & OLS & OCRS & $\mathbf{0 . 3 9}$ & 0.26 & 0.35 \\
Munnell (1990) & USA (49-85) & OLS & OCRS & $\mathbf{0 . 2 4}$ & 0.25 & 0.51 \\
Eisner (1994) & USA (49-87) & OLS & NC & $\mathbf{0 . 3 1}$ & 0.64 & -0.02 \\
Sturm and De Haan (1995) & USA (61-91) & AR(1) & NC & $\mathbf{0 . 2 7}$ & 0.19 & 0.97 \\
Vijverberg et al. (1997) & USA (49-85) & OLS & OCRS & $\mathbf{0 . 4 1}$ & 0.12 & 0.47 \\
\multicolumn{1}{c}{ OECD } & USA (58-89) & 2LS & OCRS & $\mathbf{0 . 4 8}$ & -0.92 & 1.23 \\
Bajo-Rubio and Sosvilla (1993) & SPA (64-88) & OLS & NC & $\mathbf{0 . 1 9}$ & - & - \\
Berndt and Hansson (1992) & SWE (60-88) & OLS & NC & $\mathbf{0 . 6 8}$ & 0.37 & 0.40 \\
Otto and Voss (1994) & AUS (66-90) & OLS & PFCRS & $\mathbf{0 . 3 8}$ & 0.47 & 0.53 \\
Wylie (1996) & CAN (46-91) & AR(1) & NC & $\mathbf{0 . 5 1}$ & 0.30 & 0.19 \\
\hline \hline
\end{tabular}

Note: OCRS: Overall Constant Returns to Scale, PFCRS: Private Factors Constant Returns. NC: No Constraint. Method: AR(1): Cochrane-Orcut, 2LS: Two Stage Least Square, OLS: Ordinary Least Square. $e_{g}$, $e_{k}$ and $e_{n}$ respectively denote public capital, private capital and labor elasticity.

In an attempt to explore the robustness of these findings, several authors, including Tatom (1991) or Gramlich (1994), highlighted two bias sources which could partly explain them. First, the potential presence of an endogeneity bias, stemming from the simultaneous determination of the level of production factors and the total productivity of these factors (Gramlich 1994). The second source of misspecification could come from the absence of a cointegrating relationship. Indeed, with the exception of Lau and Sin (1997), most empirical studies based on American data fail to find a cointegrating relationship for the aggregated production function extended to public capital (see, for 
example, Tatom 1991, Sturm and De Haan 1995, or Crowder and Himarios 1997). In this context, the "spurious regression" configuration can lead to a fallacious inference about the estimated parameters of the production function and particularly about the estimate of public capital elasticity, and could also induce second order biases when innovations of integrated processes are correlated.

An alternative to the level specification is to consider the production function in the first difference. However, the use of first differenced data, justified in the case of non-stationary and non-cointegrated series, generally leads to opposites findings, namely the rejection of the hypothesis of positive effects of public infrastructures on the productivity of private factors (see evidence in Table 2). Although the use of this specification seems to clearly indicate important biases in Aschauer's (1989) estimates, several authors, including the influential work of Munnell (1992), suggested that first differencing is not, in this case, the suitable method because it destroys all long-term relations that may exist among the production function variables.

Table 2: Main Empirical Results: Specifications in First Differences

\begin{tabular}{lcccc}
\hline \hline \multicolumn{1}{c}{ Study } & Country & Sample & Model & $e_{g}$ \\
Tatom (1991) & USA & $49-89$ & - & N.S. \\
Hulten and Schwab (1991) & USA & $49-85$ & NC & N.S. \\
Sturm and De Haan (1995) & USA & $49-85$ & NC & N.S. \\
& NTH & $60-90$ & OCRS & 1.16 \\
Ford and Poret (1991) & USA & $57-89$ & NC & 0.40 \\
(Strict Definition) & FRA & $67-89$ & OCRS & N.S. \\
& UK & $73-88$ & OCRS & N.S. \\
& GER & $62-89$ & NC & 0.81 \\
\hline \hline
\end{tabular}

Note: NC: No Constraint, OCRS: Overall Constant Returns to Scale, NS: Not Significant at 5\%.

These observations lead us to question the specification of the production function. If the production function is a cointegrating relationship, then the total factor productivity (TFP) is, by definition, covariance stationary. However, there is no reason to believe a priori that the Solow's residual can be represented as a stationary process (namely, contrary to most macroeconomic series), all the more that standard models of stochastic growth typically attribute the non-stationarity of the economy to the exogenous process of Solow's residual. In these models, the cointegration between factors 
and output results from the balanced growth hypothesis and does not coincide with the production function. Besides, from an empirical point of view, the production function may be represented as a cointegrating relationship only if it is properly specified and if it explicitly integrates all the potential explanatory variables of productivity, like human capital or education, research and development, measurements of organizational capital, etc., while leaving out one or more of these factors can lead to a fallacious measurement of Solow's residual. Thus, some studies, like Crowder and Himarios (1997), refute the representation of the production function as a long-term relationship, and stress out that it is a technological constraint which, date by date, links the short-run components of these variables.

Nevertheless, the rejection of the stationarity hypothesis of the TFP does not necessarily imply the absence of any cointegrating relationship between production function variables. For example, Crowder and Himarios (1997) show that American postwar data satisfy the main long-run implications of the stochastic balanced growth models, as the cointegration tests illustrate that output, as well as the stocks of private and public capital, share the same stochastic trend over the period. The presence of these long-term relations, in particular between the regressors of the equations estimated by Aschauer (1989), can thus lead to an over-estimation of public infrastructure elasticity (see Table 1). However, the first differences specification can constitute a too "radical" method (Munnell 1992), which leads too frequently to incorrectly accept the null hypothesis of zero public capital elasticity (see Table 2), since it does not take into account the long-term relations of the system.

To analyze these issues more precisely, we consider in the following a replication of these estimation methods on pseudo samples generated from a theoretical model. To ensure generality, the model used as a data generating process (DGP) in our exercise is built such as to reproduce the main long-run relationships observed in postwar American data between the variables of the production function. ${ }^{5}$

\section{The Data Generating Process (DGP)}

To assess the bias size in reported estimates of public capital elasticity, we consider a dynamic stochastic growth equilibrium (DSGE) model as a Data Generating Process

\footnotetext{
${ }^{5}$ One important aspect regarding the generality of our model is that, by the mean of different parametrizations, it can be extended to other economies.
} 
(DGP). This model is derived from the seminal growth model coined by Barro (1990) and it is based on a single-good economy, with a representative agent who maximizes her lifetime expected utility

$$
\max _{\left\{C_{t}, N_{t}\right\}_{t=0}^{\infty}} U=E_{0}\left[\sum_{t=0}^{\infty} \beta^{t} \log \left(C_{t}-B A_{t} N_{t}^{\lambda}\right)\right],
$$

where $C_{t}$ and $N_{t}$ respectively denote consumption and labor at time $t$, with $\left.\beta \in\right] 0,1[$ the discount factor. The parameter $\lambda>1$ controls the wage elasticity of labor supply, and $B>0$ is a scale parameter which determines the marginal disutility of labor. This specification of preferences implies that the choices of consumption and leisure are not independent, and, in order to get a balanced growth path, the marginal disutility of labor must grow at the same rate as the marginal utility of consumption. Such a condition is satisfied when the disutility of labor is multiplied by a term $A_{t}$, which is proportional to the balanced growth rate, as we will see below. The representative agent maximizes (1) under the following budget constraint

$$
C_{t}+I_{t} \leq(1-\tau) w_{t} N_{t}+(1-\tau) r_{t} K_{t}+(1-\tau) \pi_{t} \quad \forall t \geq 0
$$

where $w_{t}, r_{t}, \tau, I_{t}$ and $\pi_{t}$ respectively denote real wage, real interest rate, tax rate, private investments and profits.

In addition to the Solow's residual emphasized below, output $Y_{t}$ depends on the levels of private inputs, namely capital $K_{t}$ and labor $N_{t}$, and on the stock of public capital $K_{g, t}$, which is given for the firm and is assumed to have a positive externality on private factors' productivity (Barro 1990). ${ }^{6}$ The production function, with private factors constant returns to scale, is defined as

$$
Y_{t}=A_{t}^{1-e_{k}-e_{g}} N_{t}^{e_{n}} K_{t}^{e_{k}} K_{g, t}^{e_{g}}
$$

with $\left.\forall\left(e_{k}, e_{g}\right) \in\right] 0,1\left[^{2}, e_{k}+e_{g}<1\right.$ and $e_{n}+e_{k}=1$.

We assume that the TFP, denoted $A_{t}$, follows a random walk

$$
\log \left(A_{t}\right)=\log \left(A_{t-1}\right)+\epsilon_{a, t} \quad \forall t \geq 1,
$$

\footnotetext{
${ }^{6}$ In this model we consider an aggregated measure of public capital and consequently we do not use a sectoral or firm-level measure of productivity, based for instance on Data Envelopment Analysis (DEA), see the seminal contribution of Charnes, Cooper and Rhodes (1978). For recent studies that focus on the measurement of productivity at a sectoral level see Ouellette, Petit, Tessier-Parent and Vigeant (2012) for the air carriers industry or De Witte and Geys (2013) for public libraries.
} 
where $A_{0}>0$ is given and where the innovations $\epsilon_{a, t}$ are $i . i . d .\left(0, \sigma_{\epsilon_{a}}^{2}\right)$. According to (4), all increasing variables are non stationary in this model, with the exogenous growth factor being determined by $A_{t}$, namely the component of Solow's residual which is orthogonal to public services. ${ }^{7}$ Finally, we consider a log-linear law of depreciation for private capital at the rate $\left.\delta_{k} \in\right] 0,1[$

$$
K_{t+1}=A_{k} K_{t}^{1-\delta_{k}} I_{t}^{\delta_{k}} \quad A_{k}>0
$$

This latter hypothesis allows us to analytically solve the model with a strictly positive depreciation rate (Cassou and Lansing 1998).

Given the aim of our exercise, the only constraint on the theoretical model concerns its stochastic dimension. Indeed, as it will be seen later, it is necessary to introduce at least as many exogenous shocks in the theoretical model as stochastic regressors used in empirical models, in order to avoid multicollinearity. ${ }^{8}$ Since our specifications of the production function include two stochastic regressors, the data generating process of our pseudo samples must contain at least two stochastic components. Consequently, we assume that public investment is affected by a specific shock of productivity as specified in Greenwood, Hercowitz and Huffman (1988), and consider a log-linear specification of the law of accumulation of public capital

$$
K_{g, t+1}=A_{g} K_{g, t}^{1-\delta_{g}}\left(I_{g, t} V_{g, t}\right)^{\delta_{g}}
$$

with $\left.A_{g}>0, \delta_{g} \in\right] 0,1\left[\right.$, and where $V_{g, t}$ denotes the specific shock on public investment. This shock follows a stationary $A R(1)$ process

$$
\log \left(V_{g, t}\right)=\rho_{g} \log \left(V_{g, t-1}\right)+\epsilon_{g, t} \quad \forall t \geq 1
$$

with $V_{g, 0}>0,\left|\rho_{g}\right|<1$, and where innovations $\epsilon_{g, t}$ are i.i.d. $\left(0, \sigma_{g}^{2}\right)$ and can be correlated to $\epsilon_{a, t}$. As usual in this kind of models (Barro 1990, Glomm and Ravikumar 1997, Greiner and Semmler 1999, etc.), we assume that public investment is financed by a proportional income tax, namely $I_{g, t}=\tau Y_{t}$.

\footnotetext{
${ }^{7}$ Under this specification the aggregate production function, extended to public capital, can not be specified as a long-run relationship, in line with the empirical findings generally obtained from US postwar data.

${ }^{8}$ This hypothesis has no consequence on the generality of our results. Indeed, assuming that there is only one productivity shock on the TFP, or that both TFP and public capital are affected by two shocks, has no qualitative effects on our results. But, the latter case allows reducing the colinearity that could arise between our regressors with only one source of stochastic shock.
} 
Appendix A presents the outcome of the maximization of equation (1) under the constraints (2)-(7). Denoting logarithms by lower cases, we can analytically derive the dynamics of the endogenous variables in the following dynamic system

$$
\begin{aligned}
y_{t}=b_{y}+ & \frac{\lambda e_{k}}{\lambda-1+e_{k}} k_{t}+\frac{\lambda e_{g}}{\lambda-1+e_{k}} k_{g, t}+\frac{\lambda\left(1-e_{k}-e_{g}\right)-\left(1-e_{k}\right)}{\lambda-1+e_{k}} a_{t}, \\
k_{t}= & b_{k}+\left[1+\delta_{k} \frac{\lambda\left(e_{k}-1\right)+1-e_{k}}{\lambda-1+e_{k}}\right] k_{t-1}+\frac{\delta_{k} \lambda e_{g}}{\lambda-1+e_{k}} k_{g, t-1} \\
& +\delta_{k}\left[\frac{\lambda\left(1-e_{k}-e_{g}\right)-\left(1-e_{k}\right)}{\lambda-1+e_{k}}\right] a_{t-1}, \\
k_{g, t}= & b_{g}+\frac{\delta_{g} \lambda e_{k}}{\lambda-1+e_{k}} k_{t-1}+\left[1+\delta_{g} \frac{\lambda\left(e_{g}-1\right)+1-e_{k}}{\lambda-1+e_{k}}\right] k_{g, t-1} \\
& +\delta_{g}\left[\frac{\lambda\left(1-e_{k}-e_{g}\right)-\left(1-e_{k}\right)}{\lambda-1+e_{k}}\right] a_{t-1}+\delta_{g} v_{g, t-1}, \\
n_{t}= & b_{n}+\frac{e_{k}}{\lambda-1+e_{k}} k_{t}+\frac{e_{g}}{\lambda-1+e_{k}} k_{g, t}-\frac{\left[e_{k}+e_{g}\right]}{\lambda-1+e_{k}} a_{t},
\end{aligned}
$$

where $b_{y}, b_{k}, b_{g}$ and $b_{n}$ are constant (see Appendix A), and where the exogenous processes $a_{t}$ and $v_{g, t}$ are respectively defined as $a_{t}=a_{t-1}+\epsilon_{a, t}$ and $v_{g, t}=\rho_{g} v_{g, t-1}+\epsilon_{g, t}$.

\section{Stationarity, cointegrating relations and Wold's repre- sentations}

Given the aim of our study, it is crucial to show that our theoretical model, used as DGP, matches the main findings of the literature, especially in terms of stationarity / cointegrating relations for the main variables used to estimate the public capital productivity. First, most of empirical studies based on US data point out that all variables used to estimate the production function (except employment) are non-stationary (see Tatom 1991 for a survey). Second, many authors (e.g. Aaron 1990, Tatom 1991, Munnell 1992, Sturm and De Haan 1995, Otto and Voss 1997 or Sturm 1998) report that there is no cointegration between output and (public and private) inputs. Third, according to Crowder and Himarios (1997), private capital, public capital and output share the same stochastic common trend and are cointegrated with a vector $(1,-1)$.

To show that our theoretical model allows reproducing these stylized facts, we study its properties in terms of stationarity / cointegration relations. For this, consider the $V A R I M A$ representation of the vectorial process $x_{t}=\left(k_{t} k_{g, t}\right)^{\prime}$. We assume that this 
representation is defined as $A(L)(1-L) x_{t}=B(L) \varepsilon_{t}$, where $\epsilon_{t}=\left(\epsilon_{a, t} \epsilon_{g, t}\right)^{\prime}$ and $L$ is the lag operator. Using equations (9) and (10), we define these matrix polynomials as

$$
\begin{aligned}
& A(L)=\left(\begin{array}{cc}
1-\left(1+\theta_{k}\right) L & -\frac{e_{g}}{e_{k}}\left(\theta_{k}+\delta_{k}\right) L \\
-\frac{e_{k}}{e_{g}}\left(\theta_{g}+\delta_{g}\right) L & 1-\left(1+\theta_{g}\right) L
\end{array}\right),
\end{aligned}
$$

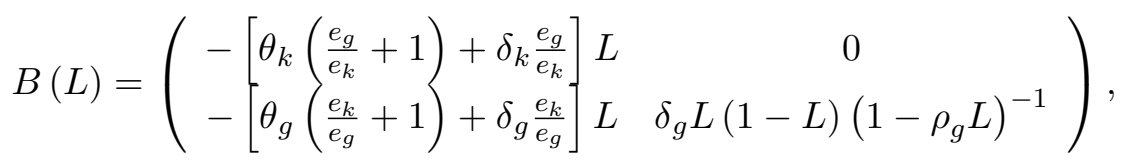

where $\theta_{k}=\delta_{k}\left[\lambda\left(e_{k}-1\right)+1-e_{k}\right] /\left(\lambda-1+e_{k}\right)$ and $\theta_{g}=\delta_{g}\left[\lambda\left(e_{g}-1\right)+1-e_{k}\right] /\left(\lambda-1+e_{k}\right)$ are two negative constants, since $\lambda>1$. Under the condition (see Appendix B) $\lambda>\left(1-e_{k}\right) /\left(1-e_{k}-e_{g}\right)$, we can apply the Wold's (1954) theorem to the process $(1-L) x_{t}$ and express it as a $V M A(\infty)$

$$
(1-L)\left(\begin{array}{l}
k_{t} \\
k_{g, t}
\end{array}\right)=\left[\frac{A^{*}(L) B(L)}{\left(1-\lambda_{1}^{-1} L\right)\left(1-\lambda_{2}^{-1} L\right)}\right]\left(\begin{array}{c}
\varepsilon_{a, t} \\
\varepsilon_{g, t}
\end{array}\right)=\left[\begin{array}{c}
H_{k}(L) \\
H_{g}(L)
\end{array}\right] \varepsilon_{t}=H(L) \epsilon_{t},
$$

with $A^{*}(L) A(L)=\operatorname{det} A(L)=\left(1-\eta_{1}^{-1} L\right)\left(1-\eta_{2}^{-1} L\right)$. The $(2,2)$ matrix polynomial $H(L)$ can be expressed as a function of the structural parameters, with

$$
\begin{aligned}
& H_{k}(L)=\frac{L}{\operatorname{det} A(L)}\left(\begin{array}{c}
\frac{e_{g}}{e_{k}} \Psi_{g}\left(\theta_{k}+\delta_{k}\right) L+\Psi_{k}\left[1-\left(1+\theta_{g}\right) L\right] \\
\frac{e_{g}}{e_{k}} \delta_{g}\left(\theta_{k}+\delta_{k}\right) L \frac{(1-L)}{\left(1-\rho_{g} L\right)}
\end{array}\right)^{\prime}, \\
& H_{g}(L)=\frac{L}{\operatorname{det} A(L)}\left(\begin{array}{c}
\frac{e_{k}}{e_{g}} \Psi_{k}\left(\theta_{g}+\delta_{g}\right) L+\Psi_{g}\left[1-\left(1+\theta_{k}\right) L\right] \\
\delta_{g}\left[1-\left(1+\theta_{k}\right) L\right] \frac{(1-L)}{\left(1-\rho_{g} L\right)}
\end{array}\right)^{\prime},
\end{aligned}
$$

where $\Psi_{k}=-\theta_{k}\left(e_{g} / e_{k}+1\right)-\delta_{k} e_{g} / e_{k}$ and $\Psi_{g}=-\theta_{g}\left(e_{k} / e_{g}+1\right)-\delta_{g} e_{k} / e_{g}$ denote two negative constants corresponding to linear combinations of parameters $\theta_{k}$ and $\theta_{g}$.

In this model, due to the balanced growth assumption, the non stationarity of the TFP, namely $a_{t}$, implies the non stationarity of both private and public capital stocks. Under the condition $\lambda>\left(1-e_{k}\right) /\left(1-e_{k}-e_{g}\right)$, public and private capital stocks are cointegrated as soon as $H(1)$ is a singular matrix. This result is ensured since $H_{k}(1)=H_{g}(1)=\left(\begin{array}{ll}1 & 0\end{array}\right)$.

Then, the normalized cointegrating vector between $k_{t}$ and $k_{g, t}$ is $(1,-1)$, while the remaining cointegrating relations in the model can be derived from it. In particular, we show that private and public capital stocks are both cointegrated with TFP $a_{t}$, a property arising from the balanced growth assumption for our theoretical model. In the same way, it is easy to see that the employment level $n_{t}$ is a stationary variable, since it 
can be expressed as a linear function of stationary processes $\left\{k_{t}-a_{t}\right\}$ and $\left\{k_{g, t}-a_{t}\right\}$, according to equation (11). Therefore, we obtain the following long-run properties.

Proposition 1 For the considered data generating process, processes $\left\{n_{t}\right\}$ and $\left\{v_{g, t}\right\}$ are covariance stationary, whereas processes $\left\{y_{t}\right\},\left\{k_{t}\right\},\left\{k_{g, t}\right\}$ and $\left\{a_{t}\right\}$ are integrated of order 1 and share the same common stochastic trend determined by $\left\{a_{t}\right\}$.

Proposition 1 implies that the main long term properties of our simple balanced growth model match the American historical observations previously mentioned. Note that the cointegrating vectors of the model do not disclose any information on the rates of return on public or private factors. These preliminary conclusions are similar to those obtained in another context by Soderlind and Vredin (1996), using a monetary business cycle model for studying the cointegrating relations between money, output, prices and interest rates.

Finally, we consider the Wold decompositions associated to processes $\left\{n_{t}\right\},\left\{k_{t}\right\}$ and $\left\{k_{g, t}\right\}$. The last two are provided by equations (15) and (16). As mentioned above, the employment dynamics (equation (11)) only depends on stationary processes $\left\{k_{t}-a_{t}\right\}$ and $\left\{k_{g, t}-a_{t}\right\}$. Since the common trend of both capital stocks is determined by $a_{t}$, the $V M A(\infty)$ representation associated to $\left\{n_{t}\right\}$ depends on the stationary component, denoted $\widetilde{H}(L)$, issued from Beveridge and Nelson's (1981) decomposition of matrix polynomial $H(L)$. This stationary component is defined as

$$
\widetilde{H}(L) \varepsilon_{t}=\left[\begin{array}{c}
\widetilde{H}_{k}(L) \\
\widetilde{H}_{g}(L)
\end{array}\right] \varepsilon_{t}=\left[\frac{H(L)-H(1)}{(1-L)}\right] \varepsilon_{t}=\left(\begin{array}{l}
k_{t}-a_{t} \\
k_{g, t}-a_{t}
\end{array}\right),
$$

since $(1-L) a_{t}=\varepsilon_{a, t}=H(1) \varepsilon_{t}$. Then, the dynamics of $n_{t}$ is simply

$$
n_{t}=b_{n}+\frac{e_{k}}{\lambda-1+e_{k}} \widetilde{H}_{k}(L) \epsilon_{t}+\frac{e_{g}}{\lambda-1+e_{k}} \widetilde{H}_{g}(L) \epsilon_{t} .
$$

These Wold representations show that all increasing endogenous variables $y_{t}, k_{t}$ and $k_{g, t}$ follow an $\operatorname{ARIMA}(3,1,3)$ process, whereas employment $n_{t}$ follows an $A R M A(3,2)$. To simplify calculus, we assume in the following null constant terms $b_{n}=b_{k}=b_{g}=0$.

\section{The estimation of the public capital elasticity: Asymp- totic results}

The goal of our study is to explain the empirical puzzle of the public capital productivity estimates. Our approach is the following: we consider a theoretical DGP, in which we 
know the exact contribution of public capital to productivity. Then, we use the same regression specifications generally used in the literature in order to estimate the public capital productivity (based on data generated by our DGP) and to compare it to the true impacts. Given the VARIMA representation of our DGP, we are able to derive the exact asymptotic distribution of the estimators of the public capital elasticity for various regression models and to advance a theoretical explanation of the potential biases. For simplicity, we focus in this section on $O L S$ estimators applied to specifications in level of the production function, while the next section analyzes both level and first-difference specifications. Let us consider the two following regression models

$$
\begin{gathered}
y_{t}-k_{t}=e_{n}\left(n_{t}-k_{t}\right)+e_{g} k_{g, t}+\mu_{1, t}, \\
y_{t}-k_{t}=e_{n}\left(n_{t}-k_{t}\right)+e_{g}\left(k_{g, t}-k_{t}\right)+\mu_{2, t} .
\end{gathered}
$$

These models, used by Aschauer (1989), allow considering various assumptions on the nature of the scale returns. First, equation (19) corresponds to the assumption of private factors' constant returns to scale (PFCRS), an assumption identical to that used in the theoretical model. Second, equation (20) corresponds to the assumption of overall constant returns to scale $(O C R S)$. Using the latter specification, Aschauer (1989) obtained a public capital elasticity of $39 \%$, i.e. higher than the estimated private capital elasticity (26\%). In the following, we derive the asymptotic distributions of the $O L S$ estimators $\widehat{e}_{n}$ and $\widehat{e}_{g}$ obtained respectively from (19) and (20).

\subsection{The private factors' constant returns to scale $(P F C R S)$ specifica- tion}

In model (19), the endogenous variable $y_{t}-k_{t}$ is stationary and the stochastic regressors $n_{t}-k_{t}$ and $k_{g, t}$ are $I(1)$. However, these regressors are cointegrated. Indeed, given our theoretical DGP, the sum of the two regressors $n_{t}-k_{t}+k_{g, t}$ is proportional to the stationary component of Beveridge and Nelson's decomposition of the vectorial process $\left(\Delta k_{t} \Delta k_{g, t}\right)^{\prime}$, which is stationary by definition. This is easily seen from the expression $\left(n_{t}-k_{t}\right)+k_{g, t}=\Phi_{1} \widetilde{H}(L) \epsilon_{t}$, where the matrix polynomial $\widetilde{H}(L)$ comes from equation (17), and where the vector $\Phi_{1}$ is defined as

$$
\Phi_{1}=\left(\frac{1}{\lambda-1+e_{k}}\right)\left[(1-\lambda) e_{k}+e_{g}-1+\lambda\right] .
$$

Thus, the PFCRS regression model leads to a particular case, in which the two stochastic regressors follow an integrated process and are cointegrated with a vector 
$(1,1)$. Consequently, the matrix of the empirical second order moments of the regressors $s_{t}=\left[\begin{array}{lll}\left(n_{t}-k_{t}\right) & k_{g, t}\end{array}\right]^{\prime}$ converges toward a distribution with a singular variancecovariance matrix (see Appendix C). This property implies that the empirical second order moments used to build $\widehat{e}_{g}$ and $\widehat{e}_{n}$ converge toward a distribution characterized by a singular variance covariance matrix. In other words, it means that the common trend of the two stochastic regressors leads to a degenerated asymptotic distribution of $\widehat{e}_{g}$ and $\widehat{e}_{n}$, since the denominator of these estimators converges toward zero. Therefore, the derivation of the asymptotic distributions of $\widehat{e}_{g}$ and $\widehat{e}_{n}$ can not be done directly starting from the specification (19), as it is necessary to transform the model before determining these asymptotic distributions.

A solution to this problem is to use a transformation of the specification (19), showing up the residual of the cointegrating relationship of the regressors and a non stationary combination of these variables (Park and Phillips 1989).

Proposition 2 The model (19) can be transformed as a triangular representation (Phillips 1991) as follows

$$
\begin{gathered}
y_{t}-k_{t}=A_{0} z_{0, t}+A_{1} z_{1, t}+\mu_{1, t}, \\
z_{i, t}=S_{i}^{\prime} s_{t}, \quad A_{i}=A S_{i}, \quad i=0,1,
\end{gathered}
$$

where $A=\left(e_{n} e_{g}\right), s_{t}=\left[\left(n_{t}-k_{t}\right) k_{g, t}\right]^{\prime}$, and where scalars $z_{0, t}$ and $z_{1, t}$ are two linear combinations of the elements of $s_{t}$, which are respectively stationary and integrated of order one, with $S=\left(S_{0}: S_{1}\right)$ an orthogonal $(2,2)$ matrix.

This transformed model allows deriving the asymptotic distributions of $\widehat{e}_{n}$ and $\widehat{e}_{g}$. The intuition is as follows. Considering a transformed model including the residual of the cointegrating relationship between $\left(n_{t}-k_{t}\right)$ and $k_{g, t}$, the corresponding variancecovariance matrix is non singular; thus, the asymptotic distributions of the $O L S$ estimators of the transformed model parameters can be determined. We then just have to express the parameters of the basic model in the form of combinations of the transformed model parameters. While controlling them by the corresponding convergence speeds, we finally obtain the asymptotic distributions of the $O L S$ estimators of the initial parameters.

The triangular representation of proposition 2 imposes some restrictions on $S_{0}$ and $S_{1}$, presented in the assumptions A1. 
Assumptions (A1) We suppose that vectors $S_{0}$ and $S_{1}$ satisfy the two following conditions: (i) $S_{0} S_{0}^{\prime}+S_{1} S_{1}^{\prime}=I_{2}$ and (ii) vector $S_{0}$ corresponds to a normalized basis of the cointegrating space of the vectorial process $\left\{s_{t}\right\}$.

The first condition $(i)$ is necessary to ensure the equivalence between the transformed model (22) and the initial specification (19). The second condition (ii) imposes that the linear combination $z_{0, t}=S_{0}^{\prime} s_{t}$ should correspond to the cointegrating residual of the long-term relationship between $\left(n_{t}-k_{t}\right)$ and $k_{g, t}$ (except for a scalar), and is thus stationary by definition. The choice of a normalized basis of the cointegrated space is however not essential, since any monotonous transformation of the cointegrating vector would allow obtaining representation (22), but it simplifies calculations. In this model, a normalized basis of the cointegrated space of the regressors $s_{t}$ is given by the vector $S_{0}=2^{-1 / 2}\left(\begin{array}{ll}1 & 1\end{array}\right)^{\prime}$. Then, we derive the expression of $S_{1}$, namely $S_{1}=S_{0}=2^{-1 / 2}\left(\begin{array}{ll}1 & 1\end{array}\right)^{\prime}$. Under the assumptions A1, the transformed model can be expressed as

$$
y_{t}-k_{t}=\frac{A_{0}}{\sqrt{2}}\left(n_{t}-k_{t}+k_{g, t}\right)+\frac{A_{1}}{\sqrt{2}}\left(n_{t}-k_{t}-k_{g, t}\right)+\widetilde{\mu}_{1, t},
$$

where $\widetilde{\mu}_{1, t}=\left(e_{n}-e_{g}\right) a_{t}, z_{0, t}=2^{-1 / 2}\left(n_{t}-k_{t}+k_{g, t}\right), z_{1, t}=2^{-1 / 2}\left(n_{t}-k_{t}-k_{g, t}\right)$, $A_{0}=\left(e_{n}+e_{g}\right) / \sqrt{2}$ and $A_{1}=\left(e_{n}-e_{g}\right) / \sqrt{2}$.

Let us now derive the asymptotic distributions of $\widehat{A}_{0}$ and $\widehat{A}_{1}$ from the triangular representation (24). We prove in Appendix D that $\widehat{A}_{0}$ converges toward a punctual mass corresponding to the correlation between $z_{0, t}$ and $\left(y_{t}-k_{t}\right)$, while estimator $\widehat{A}_{1}$ converges toward a distribution of finite variance, namely

$$
\begin{aligned}
& \widehat{A}_{0} \underset{T \rightarrow \infty}{\stackrel{p}{\longrightarrow}} \frac{E\left[z_{0, t}\left(y_{t}-k_{t}\right)\right]}{E\left(z_{0, t}^{2}\right)}, \\
& T \widehat{A}_{1} \underset{T \rightarrow \infty}{\stackrel{\mathcal{L}}{\longrightarrow}} \frac{E\left[z_{0, t}\left(y_{t}-k_{t}\right)\right] \widetilde{\Psi}_{1}-E\left(z_{0, t}^{2}\right) \widetilde{\Psi}_{0}}{\sqrt{2} E\left(z_{0, t}^{2}\right) \sigma_{a}^{2} \int_{0}^{1} W_{1}^{2}(r) d r},
\end{aligned}
$$

with stochastic variables $\widetilde{\Psi}_{0}=C \Phi_{0}^{\prime}+\sum_{v=0}^{\infty} E\left[\Delta k_{g, t}\left(y_{t-v}-k_{t-v}\right)\right]$ and $\widetilde{\Psi}_{1}=C \Phi_{1}^{\prime}+$ $\sum_{v=0}^{\infty} E\left(\Delta k_{g, t} z_{0, t-v}\right)$, where $C=H_{g}(1) P\left\{\int_{0}^{1} \widetilde{W}(r)[\widetilde{W}(r)]^{\prime} d r\right\} P^{\prime} \widetilde{H}(1)^{\prime}, E\left(\varepsilon_{t} \varepsilon_{t}^{\prime}\right)=$ $\Omega=P P^{\prime}$, and $\widetilde{W}()=.\left[W_{1}(.) W_{2}(.)\right]^{\prime}$ denotes a standard Brownian vectorial motion, $\Phi_{1}$ was defined in equation $(21)$ and $\Phi_{0}=\left(\lambda-1+e_{k}\right)^{-1}\left[\left(1-e_{k}\right)(1-\lambda) \lambda e_{g}\right]$.

Given these results, we can derive the distributions of $\widehat{e}_{n}$ and $\widehat{e}_{g}$ corresponding to the initial specification (19). 
Proposition 3 The asymptotic distribution of the OLS estimator $\widehat{e}_{g}$ based on the specification (19) is identical to the one obtained under the constraint $e_{g}=e_{n}$

$$
\widehat{e}_{g} \underset{T \rightarrow \infty}{\stackrel{p}{\longrightarrow}} \frac{E\left[\left(y_{t}-k_{t}\right)\left(n_{t}+k_{g, t}-k_{t}\right)\right]}{E\left[n_{t}+k_{g, t}-k_{t}\right]^{2}},
$$

and correspondingly

$$
\widehat{e}_{n} \underset{T \rightarrow \infty}{\stackrel{p}{\longrightarrow}} \frac{E\left[\left(y_{t}-k_{t}\right)\left(n_{t}+k_{g, t}-k_{t}\right)\right]}{E\left[n_{t}+k_{g, t}-k_{t}\right]^{2}} .
$$

Consequently, the application of $O L S$ on specification (19), used notably by Aschauer (1989), leads to a fallacious constraint, implying that the estimated elasticities of public capital and employment are asymptotically identical. This result stems from the presence of a cointegrating relationship between non stationary regressors $\left\{n_{t}-k_{t}\right\}$ and $\left\{k_{g, t}\right\}$. Intuitively, in this specification, the minimization of the variance of the residuals imposes for the right member of the equation, namely $\widehat{e}_{n}\left(n_{t}-k_{t}\right)+\widehat{e}_{g} k_{g, t}$, to be homogeneous of degree zero in the $I(1)$ terms. This condition is satisfied only if the vector $\left(\widehat{e}_{n}, \widehat{e}_{g}\right)$ is proportional to the cointegrating vector $(1,1)$. In other words, the estimators of public capital and labor elasticities asymptotically converge, as if we had the constraint $e_{n}=e_{g} \cdot{ }^{9}$ Although this result can not be straightforward extended to finite sample (see the next section), Table 1 confirms the remarkable closeness of the $O L S$ estimates of $e_{g}$ and $e_{n}$ presented by Aschauer (1989).

Let us now evaluate the correlation (27), using the Wold's decompositions of processes $\left\{y_{t}-k_{t}\right\}$ and $\left\{n_{t}+k_{g, t}-k_{t}\right\}$. Figure 1 displays this correlation for various values of the correlation of shocks $\tau_{a g}$ and of the inverse of the elasticity of labor supply $\lambda$. To compare our results to those of Aschauer (1989), the other structural parameters of the model are calibrated on American data $\left(\beta=0.98, e_{k}=0.42, \delta=0.016, \delta_{g}=0.012\right.$, $\rho_{a}=1, \rho_{g}=0.88, \sigma_{a}=0.011$ and $\left.\sigma_{g}=0.088\right)$, and in particular the public capital elasticity is set at $5 \%$ (represented by a horizontal line on the graph), namely the empirical mean of the public investment ratio from postwar data (Baxter and King 1993).

When the correlation between the two shocks is null or negative (namely $\tau_{a g} \leq$ $0)$, the estimated elasticity $\widehat{e}_{g}$ converges towards a negative quantity, while towards a positive value when this correlation is positive and high enough. In particular, we

\footnotetext{
${ }^{9}$ Moreover, this constraint makes the identification of the public capital elasticity impossible. Indeed, contrary to the case of a standard endogeneity bias, the asymptotic limit of $\widehat{e}_{g}$ cannot be expressed in an additive form, namely as a simple function of the true value of $e_{g}$ and a term of covariance of the innovations.
} 
Figure 1: Asymptotic Distribution of $\widehat{e}_{g}$ under PFCRS

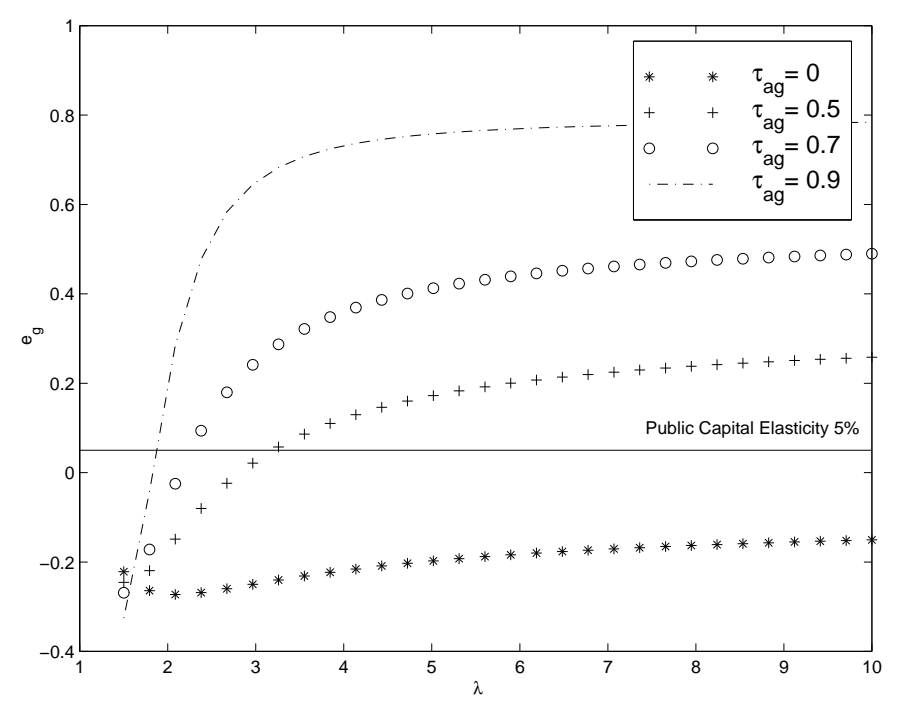

observe that for values of $\lambda$ higher than the calibrated value of 3.65 , the estimator $\widehat{e}_{g}$ tends to over-estimate the public capital elasticity. In addition, there are several values of the couple $\left(\lambda, \tau_{a g}\right)$ for which the $O L S$ estimator converges towards values over $39 \%$, namely the value estimated by Aschauer (1989) on US data, whereas the calibrated value of elasticity is only $5 \%$ in our theoretical model.

Consequently, there is a high probability that the $O L S$ estimations, under the constraint $e_{n}=e_{g}$, over-estimate the rate of return on public infrastructures. According to our model, this fallacious constraint emerges because the two regressors $\left\{n_{t}-k_{t}\right\}$ and $\left\{k_{g, t}\right\}$ share the same stochastic trend. However, such a configuration is not specific to our problem and could occur in many economic issues, as for example regarding the estimated rates of return on human capital, trade openness, etc.

\subsection{The overall constant returns to scale $(O C R S)$ specification}

The second specification of the production function, used notably by Aschauer (1989), corresponds to the hypothesis of overall constant returns to scale $(O C R S)$

$$
y_{t}-k_{t}=e_{n}\left(n_{t}-k_{t}\right)+e_{g}\left(k_{g, t}-k_{t}\right)+\mu_{2, t} .
$$

In this specification, one of the two explicative variables, namely $k_{g, t}-k_{t}$, is stationary, whereas the second, namely $n_{t}-k_{t}$, follows an $I(1)$ process. Given our theoretical 
DGP, the error term $\mu_{2, t}=\left(e_{n}-e_{g}\right) a_{t}+e_{g} k_{t}$ is non stationary. Then, this error term can be expressed as the sum of two components, one stationary and one non stationary, since $\mu_{2, t}$ is cointegrated with the regressor $n_{t}-k_{t}$, with a vector $\left(1, e_{n}\right)$. The stationary component $\widetilde{\mu}_{2, t}$ corresponds to the residual of the cointegrating relationship between $n_{t}-k_{t}$ and $\mu_{2, t}$, and is a linear combination of the elements of the polynomial matrix $\widetilde{H}(L)$ issued from the Beveridge and Nelson's decomposition of $\left(\Delta k_{t}, \Delta k_{g, t}\right)$. The non stationary component of $\mu_{2, t}$ is proportional to the regressor $n_{t}-k_{t}$. Thus, the error term can be written as $\mu_{2, t}=\widetilde{\mu}_{2, t}-e_{n}\left(n_{t}-k_{t}\right)$, where the cointegrating residual $\widetilde{\mu}_{2, t}$ is $I(0)$ by definition and can be expressed as $\widetilde{\mu}_{2, t}=e_{n} n_{t}+\left(e_{g}-e_{n}\right)\left(k_{t}-a_{t}\right)=\Phi_{2} \widetilde{H}(L) \varepsilon_{t}$, with $\Phi_{2}=\left[\left(\frac{e_{n} e_{k}}{\lambda-e_{n}}\right)+e_{g}-e_{n}\left(\frac{e_{n} e_{g}}{\lambda-e_{n}}\right)\right]$.

Using the cointegrating relationship between residual $\mu_{2, t}$ and $n_{t}-k_{t}$, we can transform the specification (20) into a model where all the explanatory variables are stationary, and in which the coefficient $e_{n}$ is not identified

$$
y_{t}-k_{t}=e_{g}\left(k_{g, t}-k_{t}\right)+\widetilde{\mu}_{2, t} .
$$

This latter expression indicates that $(i) O L S$ estimate $\widehat{e}_{g}$ of parameter $e_{g}$ in specification (20) converges in probability toward the correlation between private capital productivity and the ratio $k_{g, t}-k_{t}$, and (ii) the employment elasticity can not be identified, since under $H_{0}$ the term $n_{t}-k_{t}$ disappears.

Proposition 4 In specification (20), OLS estimators $\widehat{e}_{n}$ and $\widehat{e}_{g}$ are not convergent:

(i) the OLS estimate of public capital elasticity is affected by a standard endogeneity bias owing to the correlation between $k_{g, t}-k_{t}$ and the stationary component $\widetilde{\mu}_{2, t}$ of the population residual

$$
\widehat{e}_{g}-e_{g} \underset{T \rightarrow \infty}{\stackrel{p}{\longrightarrow}} \frac{E\left[\left(k_{g, t}-k_{t}\right) \widetilde{\mu}_{2, t}\right]}{E\left[\left(k_{g, t}-k_{t}\right)^{2}\right]}
$$

(ii) the OLS estimate of labor elasticity $\widehat{e}_{n}$ converges toward 0, because

$$
T \widehat{e}_{n} \underset{T \rightarrow \infty}{\stackrel{\mathcal{L}}{\longrightarrow}} \frac{E\left[\left(k_{g, t}-k_{t}\right)^{2}\right] \widetilde{\Psi}_{2}-E\left[\left(k_{g, t}-k_{t}\right) \widetilde{\mu}_{2, t}\right] \widetilde{\Psi}_{3}}{E\left[\left(k_{g, t}-k_{t}\right)^{2}\right] \sigma_{a}^{2} \int_{0}^{1} W_{1}^{2}(r) d r},
$$

with stochastic variables defined as

$$
\widetilde{\Psi}_{2}=-H_{g}(1) P\left\{\int_{0}^{1} \widetilde{W}(r)[\widetilde{W}(r)]^{\prime} d r\right\} P^{\prime} \widetilde{H}(1)^{\prime} \Phi_{2}^{\prime}+\sum_{v=0}^{\infty} E\left[\Delta\left(n_{t}-k_{t}\right) \widetilde{\mu}_{2, t-v}\right],
$$


$\widetilde{\Psi}_{3}=-H_{g}(1) P\left\{\int_{0}^{1} \widetilde{W}(r)[\widetilde{W}(r)]^{\prime} d r\right\} P^{\prime} \widetilde{H}(1)^{\prime} \Phi_{3}^{\prime}+\sum_{v=0}^{\infty} E\left[\Delta\left(n_{t}-k_{t}\right)\left(k_{g, t-v}-k_{t-v}\right)\right]$, with $\Phi_{3}=\left(\begin{array}{ll}-1 & 1\end{array}\right)$ and $\Phi_{2}=\left[\left(\frac{e_{n} e_{k}}{\lambda-e_{n}}\right)+e_{g}-e_{n}\left(\frac{e_{n} e_{g}}{\lambda-e_{n}}\right)\right]$.

The proof of proposition 4 is provided in Appendix E. These results clearly indicate that the application of $O L S$ on a specification in level of the production function leads to biased estimates of public capital elasticity and to an undervaluation of labor elasticity, since the corresponding estimate converges toward zero.

It is important to keep in mind that this same methodology has been used in many empirical studies devoted to the measure of return rates on public capital, and notably in Aschauer (1989). Given the same specification as (20), Aschauer obtained a very high and significant estimate of public capital elasticity (39\%), while the estimate of labor elasticity (35\%) was largely inferior to those generally estimated in two-factor production functions, where a contribution of labor around $2 / 3$ is then generally found. These observations are compatible with the conclusions of proposition 4 .

Of course, all our asymptotic results are conditional to the specifications of our theoretical DGP. However, since our theoretical model replicates the main long-run relations observed in historical American data, the use of $O L S$ on specification (20) is likely to have lead to a biased measure of the implicit rate of return on public capital in the existent literature; in particular, it is highly probable that Aschauer's (1989) results may be biased and not well grounded.

Let us now consider a numerical evaluation of these asymptotic biases (see Appendix E). Figure 2 displays the asymptotic bias for different values of $\lambda$ and $\tau_{\text {ag }}$. To ease up comparison with the PFCRS case, the other structural parameters conserve their values from the previous subsection (recall that they are calibrated on US data), and in particular the public capital elasticity is supposed to be $5 \%$ (represented again by a horizontal line).

For a positive correlation between the two shocks $\tau_{a g}>0$, observe that the endogeneity bias leads to greatly over-estimate the value of public capital elasticity. For values of $\lambda$ above the calibrated value of 3.65, the estimated elasticity lies between $28 \%$ and $80 \%$, whereas the true value is only $5 \%$. However, when the two shocks are independent $\tau_{a g}=0$, we find a negative correlation between the ratio $k_{g, t}-k_{t}$ and the stationary component of population residual $\widetilde{\mu}_{2, t}$, and the $O L S$ under-estimate the true 
Figure 2: Asymptotic Distribution of $\widehat{e}_{g}$ under $O C R S$

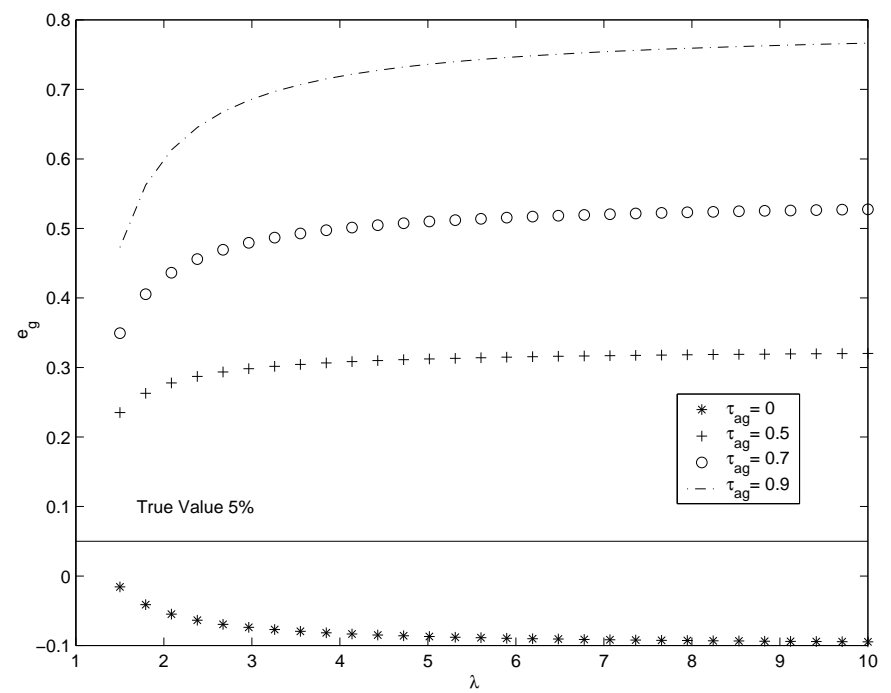

value of elasticity (5\%). In this case, the employment level, which enters the definition of residual $\widetilde{\mu}_{2, t}$, is negatively correlated to the ratio $k_{g, t}-k_{t}$, since an increase in the public capital stock implies an improvement of private productivity, which encourages the agent to substitute future labor to present labor.

\section{The estimation of the public capital elasticity: Monte Carlo simulations}

All the previous results are based on asymptotic distribution. In order to assess their robustness in finite sample, we follow recent studies that analyzed the productivity of factors (see, for example, Giraleas, Emrouznejad and Thanassoulis 2012 or Kruger 2012) and propose several Monte Carlo simulations. Considering finite samples offers an additional perspective, since most of the empirical results in the literature are based on samples of relatively small size. In these Monte Carlo simulations, the structural parameters are calibrated on US data (as this was the case in the previous section) and, in particular, the public capital elasticity $e_{g}$ is set at $5 \%$. In addition, to allow the reader assessing the robustness of our results, we realized an original companion website that allows any user reproducing our Monte Carlo simulations. This website can be visited at the following URL: 
http://www.runmycode.org/CompanionSite/site.do?siteId=165 .

The user can choose the values of calibrated parameters, the specification (level/first differences, PFCRS/OCRS), the sample size and the number of Monte Carlo simulations, and obtain online the corresponding results. ${ }^{10}$

The first two columns of Table 3 display the average estimates of the public capital and labor elasticities, obtained from 10,000 Monte Carlo simulations on pseudo samples of size between $T=50$ and $T=10000$ for the PFCRS and OCRS level specifications respectively. Monte Carlo simulations confirm our theoretical findings: when the sample size increases, the two estimators under the PFCRS specification converge towards the same value, and precisely this constraint is responsible for obtaining public capital elasticities of $30 \%$ to $40 \%$, while the true value is only $5 \%$. In addition, even for small sample size, for example $T=100$, the difference between the true $(5 \%)$ and the estimated $(13 \%)$ values of the public capital elasticity is already remarkably high, close to $150 \%$. Finally, the bias is even more pronounced for $O C R S$ specifications.

Table 3: Monte Carlo Simulations

\begin{tabular}{lccccc}
\hline \hline Sample size & \multicolumn{2}{c}{ PFCRS } & OCRS & PFCRS $(\Delta)$ & OCRS $(\Delta)$ \\
& $\widehat{e}_{g}$ & $\widehat{e}_{n}$ & $\widehat{e}_{g}$ & $\widehat{e}_{g}$ & $\widehat{e}_{g}$ \\
$T=50$ & -0.0569 & -2.0971 & 0.0413 & -0.1433 & -0.0997 \\
& $(-1.575)$ & $(-21.76)$ & $(0.579)$ & $(-3.596)$ & $(-2.216)$ \\
$T=100$ & 0.1345 & -1.1146 & 0.2524 & -0.1553 & -0.0676 \\
& $(2.929)$ & $(-12.45)$ & $(6.302)$ & $(-4.104)$ & $(-1.669)$ \\
$T=150$ & 0.2550 & -0.5690 & 0.3524 & -0.1634 & -0.0427 \\
& $(6.341)$ & $(-8.076)$ & $(10.80)$ & $(-4.521)$ & $(-1.160)$ \\
$T=200$ & 0.2976 & -0.3301 & 0.3851 & -0.1660 & -0.0295 \\
& $(8.448)$ & $(-5.488)$ & $(13.66)$ & $(-4.951)$ & $(-0.923)$ \\
$T=500$ & 0.3889 & 0.1444 & 0.4703 & -0.1838 & -0.0011 \\
& $(14.941)$ & $(4.757)$ & $(23.63)$ & $(-6.886)$ & $(-0.150)$ \\
$T=1000$ & 0.3821 & 0.2591 & 0.4856 & -0.1915 & 0.0070 \\
& $(18.104)$ & $(11.32)$ & $(29.95)$ & $(-9.114)$ & $(0.237)$ \\
$T=10000$ & 0.3388 & 0.3173 & 0.4860 & -0.2009 & 0.0156 \\
& $(40.846)$ & $(37.75)$ & $(75.32)$ & $(-26.64)$ & $(1.863)$ \\
\hline \hline
\end{tabular}

Note: This table displays the average estimates of the public capital and labor elasticities, obtained from 10,000 Monte Carlo simulations. Four specifications of the empirical model are considered: PFCRS (Private Factors Constant Returns), OCRS (Overall Constant Returns to Scale), with data expressed in level or in first differences. Average t-statistics are in parenthesis.

\footnotetext{
${ }^{10}$ The service only requires a web browser, as calculations are done on a dedicated cloud computer. Once results are ready, they are automatically displayed to the user, as a SaaS (Software as a Service). Then, she/he can gauge the potential finite sample biases for a particular specification and a particular guess on the true value of parameters.
} 
Table 4 supplements these findings by presenting the corresponding empirical frequencies of rejection for the null hypotheses $H_{0}: e_{g}=0$ and $H_{0}: e_{g}=5 \%$ respectively, at the $5 \%$ nominal level. For a sample size of $T=50$, which is roughly the average size of annual samples used in the empirical literature, we do not reject (wrongly) the nullity of the public capital elasticity in about $25 \%$ of cases, irrespective of the level specification $(P F C R S$ or $O C R S) .{ }^{11}$ Besides, observe that our findings are sensibly the same when we test for the true (calibrated) value of $e_{g}$, in the bottom part of Table 4 .

Table 4: Empirical Frequencies of Rejection of $H 0: e_{g}=\alpha$

\begin{tabular}{lcccc}
\hline \hline \multicolumn{5}{c}{$H_{0}: e_{g}=0$} \\
Sample size & PFCRS & OCRS & PFCRS $(\Delta)$ & OCRS $(\Delta)$ \\
$T=50$ & 0.7708 & 0.7743 & 0.7500 & 0.6603 \\
$T=100$ & 0.8169 & 0.8483 & 0.7620 & 0.5921 \\
$T=150$ & 0.8570 & 0.9010 & 0.8046 & 0.5389 \\
$T=200$ & 0.8764 & 0.9212 & 0.8426 & 0.5028 \\
$T=500$ & 0.9340 & 0.9781 & 0.9553 & 0.3971 \\
$T=1000$ & 0.9573 & 0.9931 & 0.9956 & 0.3480 \\
$T=10000$ & 0.9998 & 1.0000 & 1.0000 & 0.4923 \\
& \multicolumn{4}{c}{$H_{0}: e_{g}=5 \%$} \\
Sample size & PFCRS & OCRS & PFCRS $(\Delta)$ & OCRS $(\Delta)$ \\
$T=50$ & 0.7787 & 0.7708 & 0.8375 & 0.7495 \\
$T=100$ & 0.8053 & 0.8366 & 0.8777 & 0.6929 \\
$T=150$ & 0.8462 & 0.8856 & 0.9152 & 0.6535 \\
$T=200$ & 0.8693 & 0.9065 & 0.9394 & 0.6192 \\
$T=500$ & 0.9151 & 0.9666 & 0.9947 & 0.5394 \\
$T=1000$ & 0.9432 & 0.9877 & 0.9999 & 0.5319 \\
$T=10000$ & 0.9993 & 1.0000 & 1.0000 & 0.8923 \\
\hline \hline
\end{tabular}

Note: This table displays the empirical frequencies of rejection for the test of nullity of the public capital stock elasticity and the test of equality to true value (calibrated). Four specifications of the empirical model are considered: PFCRS (Private Factors Constant Returns), OCRS (Overall Constant Returns to Scale) with data expressed in level or in first differences. Average t-statistics are in parenthesis.

Let us now consider first difference specifications. As emphasized in section 2 above and Table 2, the use of first differenced data generally leads to the rejection of the hypothesis of positive effects of public infrastructures on private factors' productivity.

\footnotetext{
${ }^{11}$ Naturally, as $T$ increases, this ratio of non-rejection is decreasing.
} 
As usual, let us consider the PFCRS and $O C R S$ specifications

$$
\begin{gathered}
\Delta \widetilde{y}_{t}^{s}(\theta)-\Delta \widetilde{k}_{t}^{s}(\theta)=\widehat{e}_{n}^{s}\left[\Delta \widetilde{n}_{t}^{s}(\theta)-\Delta \widetilde{k}_{t}^{s}(\theta)\right]+\widehat{e}_{g}^{s} \Delta \widetilde{k}_{g, t}^{s}(\theta)+\widehat{\mu}_{1, t}^{s}, \\
\Delta \widetilde{y}_{t}^{s}(\theta)-\Delta \widetilde{k}_{t}^{s}(\theta)=\widehat{e}_{n}^{s}\left[\Delta \widetilde{n}_{t}^{s}(\theta)-\Delta \widetilde{k}_{t}^{s}(\theta)\right]+\widehat{e}_{g}^{s}\left[\Delta \widetilde{k}_{g, t}^{s}(\theta)-\Delta \widetilde{k}_{t}^{s}(\theta)\right]+\widehat{\mu}_{1, t}^{s},
\end{gathered}
$$

where $\widetilde{z}_{t}^{s}(\theta), z=\left\{k, k_{g}, y\right\}$, refers to a sample of the endogenous variables issued from a simulation $s$, with $s \in[1, S]$, conditional to a value $\theta$ of the set of structural parameters and to a particular realization of structural shocks. ${ }^{12}$ The last two columns of Tables 3 and 4 depict results for the specifications (32) and (33). Remark that the estimated public capital elasticity is largely under-estimated, and even negative (see Table 3 ). In addition, Table 4 shows that considering first-difference, instead of level, specifications exacerbates the failure of rejecting the null hypothesis $\widehat{e}_{g}^{s}=0$. This result is in line with the findings of the empirical literature, who often conclude to the absence of significance of the public capital elasticity on differenced data. Consequently, first differencing the data is not the suitable method in our context. This is not surprising, since we assumed a common stochastic trend for all growing variables, while first differencing the covariance stationary input $n_{t}$ generates autocorrelated residuals and thus non standard asymptotic distributions for the t-statistics. Notice that our results confirms the findings of Munnell (1992), who suggests that first differencing may be too "radical" since it destroys all the long term relations of production function variables.

\section{Conclusion}

The goal of this paper is to show that the production function approach, the most popular specification used in econometric studies based on time series, does not provide a reliable estimate of the genuine rate of return on public infrastructures. Using a DGP, built for generality such as to match the main long-term properties of the production function variables observed on US postwar historical data, we prove that two main bias sources could affect the estimates of public capital elasticity. First, a standard endogeneity bias, due to the simultaneous determination of private and public inputs. The second bias source is more original and stems from the presence of a common

\footnotetext{
${ }^{12}$ Irrespective of the considered specification, $O L S$ estimations of $e_{g}$ are polluted by the well-known problem of over-differentiation. Indeed, since $\widetilde{y}_{t}^{s}(\theta), \widetilde{k}_{t}^{s}(\theta)$ and $\widetilde{k}_{g, t}^{s}(\theta)$ are cointegrated, while $\widetilde{n}_{t}^{s}(\theta)$ is stationary, equations (32) and (33) contain first differences of stationary variables, both as independent and dependent variables.
} 
stochastic trend shared by all non stationary inputs. ${ }^{13}$ As emphasized by both the asymptotic analysis and Monte Carlo simulations, this latter bias imposes a fallacious asymptotic constraint, which forces the public capital elasticity to be equal to that of labor. Thus, the production function approach, applied to specifications in level, could widely over-estimate the macroeconomic returns on public capital, a result in line with the conclusions of Romp and De Haan (2007). In addition, we find that the traditional correction, based on a specification in first differences, could lead to a fallacious inference inducing a wrongly rejection of the null hypothesis of a positive productive contribution of infrastructures. Finally, remark that our findings are not limited to the estimation of public capital elasticity, but they can be transposed in other applied researches, as for instance the study of the human capital macroeconomic productive contribution or of any type of capital stock that could affect the TFP.

Exposing the nature and the causes of the biases affecting the estimation of public capital elasticity may facilitate the choice of methods that are immune to these shortcomings. Our results suggest an empirical strategy to correctly estimate the productivity of public capital, which would consist in removing the common stochastic trends from the non-stationary regressors (and only for these regressors). The first difference approach, developed by Tatom (1991), leads to differentiate the dependent variable and all the regressors. On the contrary, our results suggest that this transformation should not be done for the dependent variable and for some regressors, but only for the regressors that share the common stochastic trend. We leave for further research the examination of the performance of such a strategy.

\section{References}

Aaron, H. 1990. Discussion, in Is there a shortfall in public capital investment?, eds. A.H. Munnell, Federal Reserve Bank of Boston.

Aschauer, D. 1989. Is Public Expenditure Productive?, Journal of Monetary Economics, 23, 177-200.

Bajo-Rubio, O., Sosvilla-Rivero, S., 1993. Does Public Capital Affect Private Sector Performance? An Analysis of the Spanish Case, 1964-88, Economic Modelling, 10, 179-184.

Barro, R., 1990. Government Spending in a Simple Model of Endogenous Growth, Journal of Political Economy, 98, 103-130.

\footnotetext{
${ }^{13}$ Notice that our bias is equally different from the bias emphasized by De Witte and Geys (2013), in estimating the (in)efficiency of public libraries.
} 
Baxter, M., King, R., 1993. Fiscal Policy in General Equilibrium, American Economic Review, 83, 315-333.

Berndt, E., Hansson, B., 1992, Measuring the Contribution of Public Infrastructure Capital in Sweden, Scandinavian Journal of Economics, 94, 151-168.

Cassou, S., Lansing, K., 1998. Optimal Fiscal Policy, Public Capital and the Productivity Slowdown, Journal of Economic Dynamics and Control, 22, 911-935.

Charnes, A., Cooper, W., Rhodes, E., 1978. Measuring the Efficiency of Decision Making Units, European Journal of Operational Research, 2, 429-444.

Crowder, W., Himarios, D., 1997. Balanced Growth and Public Capital: an Empirical Analysis, Applied Economics, 29, 1045-1053.

De Witte, K., Geys, B., 2013. Citizen Coproduction and Efficient Public Good Provision: Theory and Evidence from Public Libraries, European Journal of Operational Research, 224, 592-602.

Eisner, R., 1994. Real Government Saving and the Future, Journal of Economic Behavior and Organization, 23, 111-126.

Ford, R., Poret, P., 1991. Infrastructures et Productivité du Secteur Privé, Revue Economique, 17, 69-95.

Giraleas, D., Emrouznejad, A., Thanassoulis, E., 2012. Productivity Change Using Growth Accounting and Frontier-Based Approaches - Evidence from a Monte Carlo Analysis, European Journal of Operational Research, 222, 673-683.

Glomm, G., Ravikumar, B., 1997. Productive Government Expenditures and LongRun Growth, Journal of Economic Dynamics and Control, 21, 183-204.

Gramlich, E., 1994. Infrastructure Investment: a Review Essay, Journal of Economic Literature, 32, 1176-1196.

Greenwood, J., Hercowitz, Z., Huffman, G., 1988. Investment, Capacity Utilization and the Real Business Cycle Theory, in Frontiers of Business Cycle Research, eds. T. Cooley, Princeton University Press.

Greiner, A, Semmler, W., 1999. An Endogenous Growth Model with Public Capital and Government Borrowing, Annals of Operations Research, 88, 65-79.

Hulten, C., Schwab, R., 1991. Is There too Little Public Capital? Infrastructure and Economic Growth, Discussion Paper, American Enterprise Institute.

Kruger, J., 2012. A Monte Carlo Study of Old and New Frontier Methods for Efficiency Measurement, European Journal of Operational Research, 222, 137-142.

Lau, S.-H., Sin, C.-Y., 1997. Public Infrastructure and Economic Growth: Time Series Properties and Evidence, Economic Record, 73, 125-135.

Munnell, A., 1990. Why has Productivity Declined? Productivity and Public Investment, New England Economic Review, Federal Reserve Bank of Boston, 3-22.

Munnell, A., 1992. Infrastructure Investment and Economic Growth, Journal of Economic Perspectives, 6, 189-198. 
Ouellette, P., Petit, P., Tessier-Parent, L.-P., Vigeant, S., 2010. Introducing Regulation in the Measurement of Efficiency, with an Application to the Canadian Air Carriers Industry, European Journal of Operational Research, 200, 216-226.

Otto, G., Voss, G., 1994. Public Capital and Private Sector Productivity, Economic Record, 70, 121-132.

Park, J., Phillips, P., 1989. Statistical Inference in Regressions with Integrated Processes: Part 2, Econometric Theory, 5, 95-131.

Phillips, P., 1991. Optimal Inference in Cointegrated Systems, Econometrica, 59, 283306.

Ram, R., Ramsey, D., 1989. Government Capital and Private Output in the United States, Economics Letters, 13, 223-226.

Ratner, J., 1983. Government Capital and the Production Function for US Private Output, Economics Letters, 13, 213-217.

Romp, W., De Haan, J., 2007. Public Capital and Economic Growth: A Critical Survey, Perspektiven der Wirtschaftspolitik, 8(s1), 6-52.

Soderlind, P., Vredin, A., 1996. Applied Cointegration Analysis in the Mirror of Macroeconomic Theory, Journal of Applied Econometrics, 11, 363-381.

Sturm, J.-E., De Haan, J., 1995. Is Public Expenditure Really Productive?, Economic Modelling, 12, 60-72.

Sturm, J.-E., 1998. Public Capital Expenditure in OECD Countries: the Causes and Impact of the Decline in Public Capital Spending, Edward Elgar.

Tatom, J., 1991. Public Capital and Private Sector Performance, Federal Reserve Bank of Saint-Louis Review, 73, 3-17.

Vijverberg, W., Vijverberg C., Gamble, J., 1997. Public Capital and Private Productivity, Review of Economics and Statistics, 79, 267-278.

Wylie, P., 1996. Infrastructure and Canadian Economic Growth 1946-1991, Canadian Journal of Economics, 29, 351-355. 


\section{Appendices: to be published as supplementary material on the web page of EJOR}

\section{Appendix A: Dynamics of production function variables}

In our model, we consider the public decisions' path $\left\{K_{g, t}, I_{g, t}\right\}_{t=0}^{\infty}$ as given and we determine the equilibrium conditionally to this path. The program is

$$
\begin{aligned}
& \max _{\left\{C_{t}, N_{t}, K_{t+1}\right\}_{t=0}^{\infty}} E_{0} \sum_{t=0}^{\infty} \beta^{t} \log \left(C_{t}-B A_{t} N_{t}^{\lambda}\right), \\
& \text { under }(1-\tau) A_{t}^{1-e_{k}-e_{g}} N_{t}^{1-e_{k}} K_{t}^{e_{k}} K_{g, t}^{e_{g}}=C_{t}+A_{k}^{-\frac{1}{\delta_{k}}} K_{t+1}^{\frac{1}{\delta_{k}}} K_{t}^{\frac{\delta_{k}-1}{\delta_{k}}} .
\end{aligned}
$$

Ex-post, the path of the public capital stock is determined by the equation $K_{g, t+1}=$ $A_{g} K_{g, t}^{1-\delta_{g}}\left(\tau Y_{t} V_{g, t}\right)^{\delta_{g}}$. The solution of the program (34) verifies the Bellman's equation for an optimal path of private capital

$$
V\left(K_{t}, K_{g, t}, A_{t}, V_{g, t}\right)=\max _{\left\{C_{t}, N_{t}, K_{t+1}\right\}}\left\{U\left(C_{t}, N_{t}\right)+\beta E_{t} V\left(K_{t+1}, K_{g, t+1}, A_{t+1}, V_{g, t+1}\right)\right\},
$$

with $K_{t+1}=A_{k} K_{t}^{1-\delta_{k}}\left[(1-\tau) A_{t}^{1-e_{k}-e_{g}} N_{t}^{1-e_{k}} K_{t}^{e_{k}} K_{g, t}^{e_{g}}-C_{t}\right]^{\delta_{k}}$, and with a transversality condition $\lim _{t \rightarrow \infty} \beta^{t} E_{0}\left\{\left[\partial V\left(S_{t+1}\right) / \partial K_{t+1}\right] K_{t}\right\}=0$. This program is solved by the method of undetermined coefficients. Given the log-linear specification of the model, we guess a log-linear form to the value function $V($.$) , given by$

$$
V(.)=V_{0}+V_{1} \log \left(K_{t}\right)+V_{2} \log \left(K_{g, t}\right)+V_{3} \log \left(A_{t}\right)+V_{4} \log \left(V_{g, t}\right) .
$$

We substitute the derivative $\partial V(.) / \partial K$ in the first order conditions of the representative agent's program, and we obtain the private investment ratio and the saving rate, denoted $s$. The saving rate is constant and implies a unity correlation between production and investment, given the log-linear specification of the model

$$
I_{t}=A_{k}^{-\frac{1}{\delta_{k}}} K_{t+1}^{\frac{1}{\delta_{k}}} K_{t}^{\frac{\delta_{k}-1}{\delta_{k}}}=s(1-\tau) Y_{t} \quad C_{t}=(1-\tau)(1-s) Y_{t},
$$

with $s=\left(\beta e_{k} \delta_{k}\right) /\left[1-\beta\left(1-\delta_{k}\right)\right]>0$, since $\beta<1$. By substituting these expressions in the first order conditions of the program, we get (8), (9), (10) and (11), and the corresponding constant terms are

$$
\begin{gathered}
b_{n}=\left[\log (1-\tau)+\log \left(1-e_{k}\right)-\log (B)-\log (\lambda)\right] /\left(\lambda-1+e_{k}\right), \\
b_{k}=\log \left(A_{k}\right)+\delta_{k}\left[\log (s)+\left(1-e_{k}\right) b_{n}+\log (1-\tau)\right], \\
b_{g}=\log \left(A_{g}\right)+\delta_{g}\left[\log (\tau)+\left(1-e_{k}\right) b_{n}\right] .
\end{gathered}
$$




\section{Appendix B: Stability conditions of $A(L)$}

Given the $V A R I M A$ representation in the main text, we must identify the conditions on structural parameters which ensure the stability of the polynomial $A($.$) , as this$ autoregressive component controls the dynamics of the growth rates of the two capital stocks.

Proposition 5 Let us note $\eta_{i} \in \mathbb{C}, i=1,2$, the roots of the polynomial $\operatorname{det} A(L)$. The process associated with the growth rates of private and public capital stocks is covariance stationary $\left(\left|\eta_{i}\right|>1\right)$ if and only if the inverse of the wage elasticity of labor supply verifies the condition $\lambda>\left(1-e_{k}\right) /\left(1-e_{k}-e_{g}\right)$.

The proof of this proposition is the following. We consider the polynomial of order two $\operatorname{det}[A(L)]=1+a L+b L^{2}$, where $a=-\left(2+\theta_{k}+\theta_{g}\right)$ and $b=\left(1+\theta_{k}\right)\left(1+\theta_{g}\right)-$ $\left(\theta_{k}+\delta_{k}\right)\left(\theta_{g}+\delta_{g}\right)$. Three constraints on parameters $a$ and $b$ insure that the roots of $A(L)$, namely $\eta_{1}$ and $\eta_{2}$, are outside the unit circle in modulus. These constraints are $b<1,1+a+b>0$ and $1-a+b>0$. Given the definition of $\theta_{k}$ and $\theta_{g}$, we can rewrite, under the hypothesis $\lambda>1$, these conditions as combinations of structural parameters

$$
\begin{gathered}
\lambda>\psi_{1}=\frac{\left(1-e_{k}\right)\left(\delta_{k}+\delta_{g}-\delta_{k} \delta_{g}\right)}{\left(1-e_{k}\right) \delta_{k}\left(1-\delta_{g}\right)+\left(1-e_{g}\right) \delta_{g}\left(1-\delta_{k}\right)+\delta_{k} \delta_{g}}, \\
\lambda>\psi_{2}=\frac{1-e_{k}}{1-e_{k}-e_{g}}, \\
\lambda>\psi_{3}=\frac{\left(1-e_{k}\right)\left[2\left(2-\delta_{k}-\delta_{g}\right)+\delta_{k} \delta_{g}\right]}{e_{k} \delta_{k}\left(1-\delta_{g}\right)+e_{g} \delta_{g}\left(1-\delta_{k}\right)+2\left(2-\delta_{k}-\delta_{g}\right)+\delta_{k} \delta_{g}} .
\end{gathered}
$$

If $\lambda>1$, condition (43) is always satisfied as soon as the depreciation rates $\delta_{k}$ and $\delta_{g}$ are inferior to unity. Condition (41) is always satisfied if $e_{k}>e_{g}\left(1-\delta_{k}\right)$, since then $\psi_{1}<1$. In other cases, we have to compare the thresholds $\psi_{1}$ and $\psi_{2}$, and find that $\psi_{1}-\psi_{2}=-\frac{\left(1-e_{k}\right)\left(e_{g} \delta_{g}+e_{k} \delta_{k}\right)}{\left(1-e_{k}-e_{g}\right)\left[\left(1-e_{k}\right) \delta_{k}\left(1-\delta_{g}\right)+\left(1-e_{g}\right) \delta_{g}\left(1-\delta_{k}\right)+\delta_{k} \delta_{g}\right]}$. This expression is strictly negative as soon as the depreciation rates are inferior to unity and $e_{k}+e_{g}<1$. Then, there is only one constraint on the parameter $\lambda$ which insures that the dynamics of capital growth rates are covariance stationary, namely $\left|\eta_{i}\right|>1, \forall i=1,2$. This constraint, which corresponds to the threshold $\psi_{2}$, is provided in proposition 5 .

\section{Appendix C: Asymptotic distributions of empirical mo- ments}

First, we can verify that the sum of the two regressors $\left(n_{t}-k_{t}\right)+k_{g, t}$ is proportional to the stationary component of Beveridge and Nelson's decomposition of the vectorial process $\left(\Delta k_{t} \Delta k_{g, t}\right)^{\prime}$, which is stationary by definition. Given the definitions of processes $\left\{n_{t}\right\},\left\{k_{t}\right\}$ and $\left\{k_{g, t}\right\}$ (equations (9), (10) and (11)), we have

$$
\begin{aligned}
n_{t}-k_{t}+k_{g, t} & =\left(\frac{1-\lambda}{\lambda-1+e_{k}}\right)\left(k_{t}-k_{g, t}\right)+\left(\frac{e_{k}+e_{g}}{\lambda-1+e_{k}}\right)\left(k_{g, t}-a_{t}\right) \\
& =\left(\frac{1-\lambda}{\lambda-1+e_{k}}\right)\left(k_{t}-a_{t}\right)+\left(\frac{e_{k}+e_{g}-1+\lambda}{\lambda-1+e_{k}}\right)\left(k_{g, t}-a_{t}\right) .
\end{aligned}
$$


Given that the stationary component of Beveridge and Nelson's decomposition is defined as $\widetilde{H}(L) \varepsilon_{t}=\left[\left(k_{t}-a_{t}\right)\left(k_{g, t}-a_{t}\right)\right]^{\prime}$, we can express the sum $n_{t}-k_{t}+k_{g, t}$ as $n_{t}-k_{t}+k_{g, t}=\Phi_{1} \widetilde{H}(L) \varepsilon_{t}$, where the vector $\Phi_{1}$ is defined as in equation (21) by $\Phi_{1}=\left(\frac{1}{\lambda-1+e_{k}}\right)\left[(1-\lambda) e_{k}+e_{g}-1+\lambda\right]$.

It implies that the regressors $\left(n_{t}-k_{t}\right)$ and $k_{g, t}$ share the same stochastic trend. In an obvious way, this result implies the singularity of the asymptotic variance-covariance matrix of the empirical second order moments of the regressors. Indeed, by identification we have $\Delta\left(n_{t}-k_{t}\right)=\left[(1-L) \Phi_{1} \widetilde{H}(L)-H_{g}(L)\right] \varepsilon_{t}$ and $\Delta k_{g, t}=H_{g}(L) \varepsilon_{t}$.

Now, consider the vector $s_{t}=\left[\begin{array}{lll}\left(n_{t}-k_{t}\right) & k_{g, t}\end{array}\right]^{\prime}$. Let us denote $E\left(\varepsilon_{t} \varepsilon_{t}^{\prime}\right)=\Omega=P P^{\prime}$ and $\Phi(L)=\left[(1-L) \Phi_{n} \widetilde{H}(L)-H_{g}(L) H_{g}(L)\right]^{\prime}$. By application of the functional central limit theorem and the continuous mapping theorem, we can derive the asymptotic distributions of the corresponding empirical moments

$$
\frac{1}{T^{2}} \sum_{t=1}^{T} s_{t} s_{t}^{\prime} \underset{T \rightarrow \infty}{\stackrel{\mathcal{L}}{\longrightarrow}} \Phi(1) P\left\{\int_{0}^{1} \widetilde{W}(r)[\widetilde{W}(r)]^{\prime} d r\right\} P^{\prime} \Phi(1)^{\prime}+\frac{1}{T^{2}} O p(T),
$$

where $\widetilde{W}()=.\left[W_{1}(.) W_{2}(.)\right]^{\prime}$ is a standard vectorial Brownian motion. Given the definition of $\widetilde{H}(L)$ and $H_{g}(L)$, we can verify the singularity of the asymptotic covariance matrix of the system

$$
\frac{1}{T^{2}} \sum_{t=1}^{T} x_{t} x_{t}^{\prime} \underset{T \rightarrow \infty}{\stackrel{\mathcal{L}}{\longrightarrow}} \sigma_{a}^{2}\left(\begin{array}{cc}
1 & -1 \\
-1 & 1
\end{array}\right) \int_{0}^{1} W_{1}(r)^{2} d r .
$$

\section{Appendix D: Asymptotic distribution of $\widehat{e}_{g}$ under the $P F C R S$ hypothesis}

In equation (19), $\widehat{A}_{0}$ and $\widehat{A}_{1}$ are respectively defined as

$$
\begin{gathered}
\widehat{A}_{0}=\frac{T^{-2} \sum_{t=1}^{T}\left(z_{1, t}^{2}\right) T^{-1} \sum_{t=1}^{T}\left[z_{0, t}\left(y_{t}-k_{t}\right)\right]-\left(T^{-1}\right) T^{-1} \sum_{t=1}^{T}\left(z_{1, t} z_{0, t}\right) T^{-1} \sum_{t=1}^{T}\left[z_{1, t}\left(y_{t}-k_{t}\right)\right]}{T^{-1} \sum_{t=1}^{T}\left(z_{0, t}^{2}\right) T^{-2} \sum_{t=1}^{T}\left(z_{1, t}^{2}\right)-\left[T^{-1} \sum_{t=1}^{T}\left(z_{1, t} z_{0, t}\right)\right]^{2}\left(T^{-1}\right)}, \\
T \widehat{A}_{1}=\frac{T^{-1} \sum_{t=1}^{T}\left(z_{0, t}^{2}\right) T^{-1} \sum_{t=1}^{T}\left[z_{1, t}\left(y_{t}-k_{t}\right)\right]-T^{-1} \sum_{t=1}^{T}\left(z_{1, t} z_{0, t}\right) T^{-1} \sum_{t=1}^{T}\left[z_{0, t}\left(y_{t}-k_{t}\right)\right]}{T^{-1} \sum_{t=1}^{T}\left(z_{0, t}^{2}\right) T^{-2} \sum_{t=1}^{T}\left(z_{1, t}^{2}\right)-\left(T^{-1}\right)\left[T^{-1} \sum_{t=1}^{T}\left(z_{1, t} z_{0, t}\right)\right]^{2}} .
\end{gathered}
$$

Given the dynamic properties of the theoretical model, Wold's decompositions associated to processes $\left\{z_{0, t}\right\},\left\{z_{1, t}\right\}$ and to the endogenous variable $\left\{y_{t}-k_{t}\right\}$ of the transformed model (24) are

$$
y_{t}-k_{t}=\Phi_{0} \widetilde{H}(L) \epsilon_{t},
$$




$$
\begin{aligned}
\sqrt{2} z_{0, t} & =n_{t}-k_{t}+k_{g, t}=\Phi_{1} \widetilde{H}(L) \epsilon_{t}, \\
\sqrt{2} \Delta z_{1, t} & =\Delta\left[n_{t}-k_{t}-k_{g, t}\right]=z_{0, t}-2 k_{g, t} \\
& =\left[(1-L) \Phi_{1} \widetilde{H}(L)-2 H_{g}(L)\right] \varepsilon_{t},
\end{aligned}
$$

where the polynomial vector $\widetilde{H}(L)$ corresponds to the stationary component of the Beveridge and Nelson's decomposition of the process $\left(\Delta k_{t} \Delta k_{g, t}\right)^{\prime}$ (equation (17)), and where vectors $\Phi_{0}$ and $\Phi_{1}$ are defined in the main text (see section 5 ). Then, we derive the asymptotic distributions of the corresponding empirical moments

$$
\begin{aligned}
\frac{1}{T^{2}} \sum_{t=1}^{T} z_{1, t}^{2} & =\frac{1}{T^{2}} \sum_{t=1}^{T}\left(z_{0, t}-\sqrt{2} k_{g, t}\right)^{2} \\
& =\frac{2}{T^{2}} \sum_{t=1}^{T} k_{g, t}^{2}+\frac{1}{T} O p(T) \underset{T \rightarrow \infty}{\stackrel{\mathcal{L}}{\longrightarrow}} 2 \sigma_{a}^{2} \int_{0}^{1} W_{1}(r)^{2} d r \\
\frac{1}{T} \sum_{t=1}^{T}\left[z_{0, t}\left(y_{t}-k_{t}\right)\right] \underset{T \rightarrow \infty}{\stackrel{p}{\longrightarrow}} E\left[z_{0, t}\left(y_{t}-k_{t}\right)\right] & \frac{1}{T} \sum_{t=1}^{T} z_{0, t}^{2} \underset{T \rightarrow \infty}{\stackrel{p}{\longrightarrow}} E\left(z_{0, t}^{2}\right) .
\end{aligned}
$$

In the same way, we show that

$$
\begin{array}{rl}
\frac{1}{T} \sum_{t=1}^{T} z_{0, t} z_{1, t} & =\frac{1}{T} \sum_{t=1}^{T} z_{0, t}^{2}-\sqrt{2} \frac{1}{T} \sum_{t=1}^{T} z_{0, t} k_{g, t} \\
\underset{T \rightarrow \infty}{\mathcal{L}} & E\left(z_{0, t}^{2}\right)-\sqrt{2} H_{g}(1) P\left\{\int_{0}^{1} \widetilde{W}(r)[\widetilde{W}(r)]^{\prime} d r\right\} P^{\prime} \widetilde{H}(1)^{\prime} \Phi_{1}-\sqrt{2} \Lambda_{1},
\end{array}
$$

where $\widetilde{W}()=.\left[W_{1}(.) W_{2}(.)\right]^{\prime}$ denotes a standard vectorial Brownian motion, $E\left(\varepsilon_{t} \varepsilon_{t}^{\prime}\right)=$ $\Omega=P P^{\prime}$ and $\Lambda_{1}=\sum_{v=0}^{\infty} E\left(\Delta k_{g, t} z_{0, t-v}\right)$. Finally, we have

$$
\begin{aligned}
\frac{1}{T} \sum_{t=1}^{T} z_{1, t}\left(y_{t}-k_{t}\right)=\frac{1}{T} \sum_{t=1}^{T} z_{0, t}\left(y_{t}-k_{t}\right)-\sqrt{2} \frac{1}{T} \sum_{t=1}^{T} k_{g, t}\left(y_{t}-k_{t}\right) \\
\underset{T \rightarrow \infty}{\stackrel{\mathcal{L}}{\longrightarrow}} E\left[z_{0, t}\left(y_{t}-k_{t}\right)\right]-\sqrt{2} H_{g}(1) P\left\{\int_{0}^{1} \widetilde{W}(r)[\widetilde{W}(r)]^{\prime} d r\right\} P^{\prime} \widetilde{H}(1)^{\prime} \Phi_{0}-\sqrt{2} \Lambda_{0},
\end{aligned}
$$

with $\Lambda_{0}=\sum_{v=0}^{\infty} E\left[\Delta k_{g, t}\left(y_{t-v}-k_{t-v}\right)\right]$. Then, the asymptotic distribution of $\widehat{A}_{0}$ can be immediately derived from

$$
\widehat{A}_{0}=\frac{T^{-2} \sum_{t=1}^{T}\left(z_{1, t}^{2}\right) T^{-1} \sum_{t=1}^{T}\left[z_{0, t}\left(y_{t}-k_{t}\right)\right]-T^{-3} O p\left(T^{2}\right)}{T^{-1} \sum_{t=1}^{T}\left(z_{0, t}^{2}\right) T^{-2} \sum_{t=1}^{T}\left(z_{1, t}^{2}\right)-T^{-3} O p\left(T^{2}\right)} \underset{T \rightarrow \infty}{\stackrel{\mathcal{L}}{\longrightarrow}} \frac{E\left[z_{0, t}\left(y_{t}-k_{t}\right)\right]}{E\left(z_{0, t}^{2}\right)}=h_{0} .
$$


The estimator $\widehat{A}_{0}$ converges in distribution toward a null punctual mass. Given the definition of $\widehat{A}_{1}$, we also obtain

$$
T \widehat{A}_{1} \underset{T \rightarrow \infty}{\stackrel{\mathcal{L}}{\longrightarrow}} \frac{E\left[z_{0, t}\left(y_{t}-k_{t}\right)\right] \widetilde{\Psi}_{1}-E\left(z_{0, t}^{2}\right) \widetilde{\Psi}_{0}}{\sqrt{2} E\left(z_{0, t}^{2}\right) \sigma_{a}^{2} \int_{0}^{1} W_{1}^{2}(r) d r}
$$

where the stochastic variables $\widetilde{\Psi}_{j}, j=(1,2)$ are

$$
\widetilde{\Psi}_{j}=H_{g}(1) P\left\{\int_{0}^{1} \widetilde{W}(r)[\widetilde{W}(r)]^{\prime} d r\right\} P^{\prime} \widetilde{H}(1)^{\prime} \Phi_{j}^{\prime}+\Lambda_{j} \quad \forall j=0,1 .
$$

\section{Appendix E: Asymptotic distribution of $\widehat{e}_{g}$ under the $O C R S$ hypothesis}

The Wold's decompositions of processes $\left\{k_{g, t}-k_{t}\right\},\left\{n_{t}-k_{t}\right\}$ and $\left\{y_{t}-k_{t}\right\}$ are

$$
\begin{gathered}
y_{t}-k_{t}=\Phi_{0} \widetilde{H}(L) \epsilon_{t}, \\
k_{g, t}-k_{t}=\Phi_{3} \widetilde{H}(L) \epsilon_{t}, \\
\Delta\left(n_{t}-k_{t}\right)=\left[(1-L) \Phi_{1} \widetilde{H}(L)-H_{g}(L)\right] \epsilon_{t},
\end{gathered}
$$

where the polynomial vector $H_{g}(L)$ and vectors $\Phi_{0}, \Phi_{1}$ and $\Phi_{2}$ have been previously defined. We note $\Phi_{3}=\left(\begin{array}{ll}-1 & 1\end{array}\right)$. Then, by application of the functional central limit and the continuous mapping theorems, we get

$$
\begin{aligned}
& \frac{1}{T^{2}} \sum_{t=1}^{T}\left(n_{t}-k_{t}\right)^{2}=\frac{1}{T^{2}} \sum_{t=1}^{T} k_{t}^{2}+\frac{1}{T} O p(T) \underset{T \rightarrow \infty}{\stackrel{\mathcal{L}}{\longrightarrow}} 4 \sigma_{a}^{2} \int_{0}^{1} W_{1}(r)^{2} d r, \\
& \frac{1}{T} \sum_{t=1}^{T}\left[\left(k_{g, t}-k_{t}\right) \widetilde{\mu}_{2, t}\right] \underset{T \rightarrow \infty}{\stackrel{p}{\longrightarrow}} E\left[\left(k_{g, t}-k_{t}\right) \widetilde{\mu}_{2, t}\right], \\
& \frac{1}{T} \sum_{t=1}^{T}\left(k_{g, t}-k_{t}\right)^{2} \underset{T \rightarrow \infty}{\stackrel{p}{\longrightarrow}} E\left[\left(k_{g, t}-k_{t}\right)^{2}\right],
\end{aligned}
$$

where $W_{1}($.$) is a standard scalar Brownian motion. In the same way, we find$

$$
\begin{gathered}
\frac{1}{T} \sum_{t=1}^{T}\left(n_{t}-k_{t}\right) \widetilde{\mu}_{2, t} \underset{T \rightarrow \infty}{\stackrel{\mathcal{L}}{\longrightarrow}}-H_{g}(1) P\left\{\int_{0}^{1} \widetilde{W}(r)[\widetilde{W}(r)]^{\prime} d r\right\} P^{\prime} \widetilde{H}(1)^{\prime} \Phi_{2}^{\prime}+\Lambda_{2}, \\
\frac{1}{T} \sum_{t=1}^{T}\left(n_{t}-k_{t}\right)\left(k_{g, t}-k_{t}\right) \underset{T \rightarrow \infty}{\stackrel{\mathcal{L}}{\longrightarrow}}-H_{g}(1) P\left\{\int_{0}^{1} \widetilde{W}(r)[\widetilde{W}(r)]^{\prime} d r\right\} P^{\prime} \widetilde{H}(1)^{\prime} \Phi_{3}^{\prime}+\Lambda_{3},
\end{gathered}
$$


where $E\left(\varepsilon_{t} \varepsilon_{t}^{\prime}\right)=\Omega=P P^{\prime}$, and where $\widetilde{W}()=.\left[W_{1}(.) W_{2}(.)\right]^{\prime}$ denotes a standard vectorial Brownian motion, with $\Lambda_{3}=\sum_{v=0}^{\infty} E\left[\Delta\left(n_{t}-k_{t}\right)\left(k_{g, t-v}-k_{t-v}\right)\right]$ and $\Lambda_{2}=$ $\sum_{v=0}^{\infty} E\left[\Delta\left(n_{t}-k_{t}\right) \widetilde{\mu}_{2, t-v}\right]$.

Then, we transform the expression of $\widehat{e}_{g}$ in order to control for the different speeds of convergence

$$
\widehat{e}_{g}-e_{g}=\frac{\sum_{t=1}^{T}\left[\frac{\left(n_{t}-k_{t}\right)^{2}}{T^{2}}\right] \sum_{t=1}^{T}\left[\frac{\left(k_{g, t}-k_{t}\right) \tilde{\mu}_{2, t}}{T}\right]-\left(\frac{1}{T}\right) \sum_{t=1}^{T}\left[\frac{\left(n_{t}-k_{t}\right)\left(k_{g, t}-k_{t}\right)}{T}\right] \sum_{t=1}^{T}\left[\frac{\left(n_{t}-k_{t}\right) \widetilde{\mu}_{2, t}}{T}\right]}{\sum_{t=1}^{T}\left[\frac{\left(n_{t}-k_{t}\right)^{2}}{T^{2}}\right] \sum_{t=1}^{T}\left[\frac{\left(k_{g t}-k_{t}\right)^{2}}{T}\right]-\left(\frac{1}{T}\right)\left[\sum_{t=1}^{T} \frac{\left(n_{t}-k_{t}\right)\left(k_{g, t}-k_{t}\right)}{T}\right]^{2}} .
$$

Given previous results, we obtain

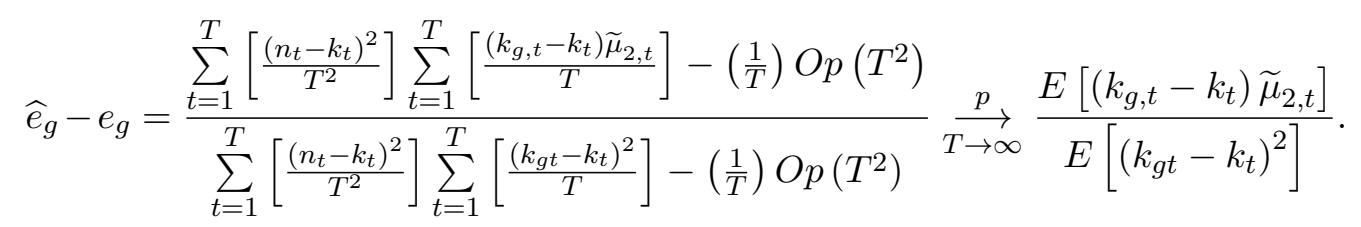

The centered estimator $\widehat{e}_{g}-e_{g}$ converges in distribution toward a punctual mass (this result ensures the convergence in probability), corresponding to the correlation between $k_{g, t}-k_{t}$ and $\widetilde{\mu}_{2, t}$. By developing the expression of the stationary component $\widetilde{\mu}_{2, t}$, we can rewrite the bias on $\widehat{e}_{g}$ as a linear function of the stationary components of the Beveridge and Nelson's decomposition of the process $\left(\Delta k_{t} \Delta k_{g, t}\right)^{\prime}$, since we have

$$
\begin{aligned}
\frac{E\left[\left(k_{g, t}-k_{t}\right) \tilde{\mu}_{2, t}\right]}{E\left[\left(k_{g t}-k_{t}\right)^{2}\right]} & =\left(1-e_{k}-e_{g}\right) \frac{E\left[\left(k_{g, t}-k_{t}\right)\left(a_{t}-k_{t}\right)\right]}{E\left[\left(k_{g, t}-k_{t}\right)^{2}\right]}+\left(1-e_{k}\right) \frac{E\left[\left(k_{g, t}-k_{t}\right) n_{t}\right]}{E\left[\left(k_{g, t}-k_{t}\right)^{2}\right]} \\
& =\frac{\Phi_{3}\left(\sum_{v=0}^{\infty} \widetilde{H}_{v} \Omega \widetilde{H}_{v}^{\prime}\right) \Phi_{2}^{\prime}}{\Phi_{3}\left(\sum_{v=0}^{\infty} \widetilde{H}_{v} \Omega \widetilde{H}_{v}^{\prime}\right) \Phi_{3}^{\prime}} .
\end{aligned}
$$

In the same way, it is possible to derive the asymptotic distribution of $\widehat{e}_{n}$. We consider the following definition

$$
T \widehat{e}_{n}=\frac{\sum_{t=1}^{T}\left[\frac{\left(k_{g, t}-k_{t}\right)^{2}}{T}\right] \sum_{t=1}^{T}\left[\frac{\left(n_{g, t}-k_{t}\right) \widetilde{\mu}_{2, t}}{T}\right]-\sum_{t=1}^{T}\left[\frac{\left(n_{t}-k_{t}\right)\left(k_{g, t}-k_{t}\right)}{T}\right] \sum_{t=1}^{T}\left[\frac{\left(k_{g, t}-k_{t}\right) \widetilde{\mu}_{2, t}}{T}\right]}{\sum_{t=1}^{T}\left[\frac{\left(n_{t}-k_{t}\right)^{2}}{T^{2}}\right] \sum_{t=1}^{T}\left[\frac{\left(k_{g t}-k_{t}\right)^{2}}{T}\right]-\left(\frac{1}{T}\right)\left[\sum_{t=1}^{T} \frac{\left(n_{t}-k_{t}\right)\left(k_{g, t}-k_{t}\right)}{T}\right]^{2}},
$$

and find $T \widehat{e}_{n} \underset{T \rightarrow \infty}{\stackrel{\mathcal{L}}{\longrightarrow}} \frac{E\left[\left(k_{g, t}-k_{t}\right)^{2}\right] \widetilde{\Psi}_{2}-E\left[\left(k_{g, t}-k_{t}\right) \widetilde{\mu}_{2, t}\right] \widetilde{\Psi}_{3}}{E\left[\left(k_{g, t}-k_{t}\right)^{2}\right] \sigma_{a}^{2} \int_{0}^{1} W_{1}^{2}(r) d r}$, where stochastic variables $\widetilde{\Psi}_{2}$ and $\widetilde{\Psi}_{3}$ are defined as $\widetilde{\Psi}_{j}=-H_{g}(1) P\left\{\int_{0}^{1} \widetilde{W}(r)[\widetilde{W}(r)]^{\prime} d r\right\} P^{\prime} \widetilde{H}(1)^{\prime} \Phi_{j}^{\prime}+\Lambda_{j} \quad \forall j=2,3$. 